\title{
NUMERICAL SIMULATION OF THE PUNCHING SHEAR BEHAVIOUR OF SELF- COMPACTING FIBRE REINFORCED FLAT SLABS
}

Marcos D.E. Teixeira ${ }^{\text {a }}$, Joaquim A.O. Barros ${ }^{\text {b }}$, Vítor M.C.F. Cunha ${ }^{c}$, Bernardo N. Moraes-Neto ${ }^{\text {d }}$, António Ventura-

\author{
Gouveia $^{\mathrm{e}}$
}

a University of Minho, ISISE, Dep. Civil Eng., School of Eng., Campus Azurém, Guimarães, Portugal, marcos.teixeira@civil.uminho.pt.

b University of Minho, ISISE, Dep. Civil Eng., School of Eng., Campus Azurém, Guimarães, Portugal, barros@civil.uminho.pt.

c University of Minho, ISISE, Dep. Civil Eng., School of Eng., Campus Azurém, Guimarães, Portugal, vcunha@civil.uminho.pt.

${ }^{d}$ University of Minho/University of Brasília-UnB, Dep. Civil Eng., School of Eng., Campus Azurém, Guimarães, Portugal,bnmn@hotmail.com

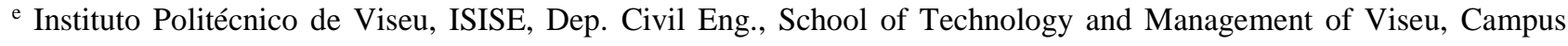
Politécnico, Viseu, Portugal, ventura@estgv.ipv.pt

\footnotetext{
Abstract

This paper presents the numerical simulations of the punching behaviour of centrally loaded steel fibre reinforced selfcompacting concrete (SFRSCC) flat slabs. Eight half scaled slabs reinforced with different content of hooked-end steel fibres $\left(0,60,75\right.$ and $\left.90 \mathrm{~kg} / \mathrm{m}^{3}\right)$ and concrete strengths of 50 and $70 \mathrm{MPa}$ were tested and numerically modelled. Moreover, a total of 54 three-point bending tests were carried out to assess the post-cracking flexural tensile strength. All the slabs had a relatively high conventional flexural reinforcement in order to promote the occurrence of punching failure mode. Neither of the slabs had any type of specific shear reinforcement rather than the contribution of the steel fibres. The numerical simulations were performed according to the Reissner-Mindlin theory under the finite element method framework. Regarding the classic formulation of the Reissner-Mindlin theory, in order to simulate the progressive damage induced by cracking, the shell element is discretized into layers, being assumed a plane stress state in each layer. The numerical results are, then, compared with the experimental ones and it is possible to notice that they accurately predict the experimental force-deflection relationship. The type of failure observed experimentally was also predicted in the numerical simulations.
} 
Keywords: Flat slab; Punching; Steel fibre reinforced self-compacting concrete; FEM analysis. 


\section{INTRODUCTION}

The use of reinforced concrete (RC) flat slabs supported directly on RC columns is a well-accepted structural system within the building construction, since it has a quite reasonable construction flexibility allowing spans with moderate lengths between columns of about 4.5 to $6.0 \mathrm{~m}[1,2]$. Considering their constructive and architectural advantages, flat slabs are mostly used in office, residential and parking buildings [3]. The flexural resistance of this structural system can be achieved with relatively small thicknesses for the slab's height. However, in order to avoid the brittle punching shear failure mode some specific design measures are required. The latter could be overcome with either the introduction of capitals or the inclusion of shear reinforcement. Nevertheless, these solutions are a step down on the construction efficiency. The design of these slabs is governed by both serviceability conditions and ultimate limit states under punching shear [4]. According to the available research, the punching behaviour of RC flat slabs can be improved by adopting distinct strategies such as: using a high strength class concrete [5], additional shear reinforcement [6] and discrete fibres (in particular steel fibres) [7-9]. When a hybrid reinforcement is used (i.e. rebar + discrete fibres), the steel fibres mainly confer the punching resistance, whilst the steel bars guarantee the flexural reinforcement [10].

Fibre reinforced concrete (FRC) is mostly applied in industrial pavements, precast elements and in tunnelling. When used in large structural elements, FRC can contribute to cost reductions, since the man-labour needed for placing the conventional reinforcement is decreased (due to the fact that the reinforcement density is smaller when compared with conventional RC) [11] or even eliminated if steel fibres replace all the conventional reinforcement. Better crack resistance, ductility and toughness are among the improvements provided by fibre reinforcement. It is widely acknowledged that there are several advantages in using FRC rather than plain concrete, i.e. greater residual tensile strengths, resistance to fatigue, impact, blast loading and abrasion. Moreover, when comparing FRC with conventional mesh / bar reinforced concrete, there are also some benefits such as: increased ultimate flexural and shear strength, increased toughness fatigue and impact resistance, and better stress redistribution in the concrete composite. The application of FRC for retrofitting and seismic design purposes has also a particular interest [12-14]. For slabs on-grade, the exclusive use of steel fibre as reinforcement could be a viable and economical alternative to conventional reinforced concrete. According to [15, 16] fibre contents ranging from 20 to $60 \mathrm{~kg} / \mathrm{m}^{3}$ should be used for this structural system. On the other hand, for suspended slabs, the exclusive use of steel fibre as reinforcement is still scarce. The outcome of FRC with enhanced mechanical strengths has been pushing the span limits upwards. Recent pilot experiences [17-19] show the feasibility of building elevated FRC slabs with 5-8m spans (using high percentages of fibres). The results obtained so far in these pilot experiences appear promising, but they fail to address several important issues. 
If fibres are properly selected in terms of type and content, they can provide effective reinforcement mechanisms to avoid the punching brittle collapse [20]. The fibre reinforcement effectiveness is not solely dependent of the type and content of fibres, the casting procedure and both rheological and mechanical properties of the concrete also influence the reinforcement effectiveness. Since steel fibres have the highest specific weight amongst the steel fibre reinforced concrete (SFRC) constituents, these fibres have a tendency to segregate towards the bottom surface, leading to a lower fibre content near the top surface $[21,22]$. In concrete matrices with high flowability, such is the case of self-compacting concrete (SCC), the effect of fibre segregation is mainly due to the rheological properties of the matrix in the fresh state [23]. The fibre segregation may lead to an anisotropic behaviour with different flexural capacity for positive and negative curvatures.

Several authors have proposed analytical expressions to estimate the contribution of fibres for the punching resistance based on the results obtained in experimental programs. Harajli et al. [24] have suggested a design equation to predict the increase in ultimate punching capacity of concrete slabs due to the addition of deformed steel fibres. This simple equation is based in the experimental results obtained by these authors and another ones available in the literature. A theoretical approach to model the punching resistance of interior slab-column connections using SFRC is presented by Choi et al [25]. According to Nguyen-Minh et al. [9] this formulation does not assure a good agreement with their experimental results. More recently, Ragab [26] has simulated numerically nine steel fibre reinforced self-compacting concrete (SFRSCC) flat slabs by performing material nonlinear analysis with software based on the finite element method (FEM). Moreover, this author carried out a parametric study to analyse the influence of the ratio of flexural reinforcement (for both positive and negative bending moments) and the volume of steel fibre in the slab's behaviour. In this model, the steel fibre reinforced concrete matrix is simulated by solid elements, while the steel bars were simulated by a link element. It is possible to notice that this model has predicted with good accuracy the experimental results.

In this work, punching shear test results and numerical simulations are presented and discussed. Eight half scaled slabs reinforced with different content of hooked-end steel fibres $\left(0,60,75\right.$ and $\left.90 \mathrm{~kg} / \mathrm{m}^{3}\right)$ and concrete strengths $(50$ and 70 $\mathrm{MPa}$ ) were tested and numerically modelled. Moreover, a total of 54 three-point bending tests were carried out to assess the post-cracking flexural tensile strength. All SFRC slabs were heavily reinforced with conventional flexural reinforcement in order to promote the occurrence of punching failure mode. Neither of the slabs had any type of specific shear reinforcement rather than the contribution of the steel fibres. The numerical simulations were performed by adopting a FEM approach based on the Reissner-Mindlin shell theory. Regarding the classic formulation of the Reissner-Mindlin shell theory, to simulate the progressive damage induced by cracking propagation, the shell element is discretized into 
layers, being assumed a plane stress state in each layer. For the two out-of-plane shear components a total approach is adopted, whereas for the in-plane components it was adopted an incremental approach. The numerical results are compared to the experimental ones, and good predictions in terms of force-deflection relationship were obtained. The type of failure observed experimentally was also predicted in the numerical simulations.

\section{EXPERIMENTAL PROGRAM}

\subsection{Concrete properties, specimen geometry and test setup}

Eight half scaled flat slabs prototypes with the dimensions of $2550 \times 2550 \times 150 \mathrm{~mm}^{3}$ (Figure 1) were centrally and vertically loaded. Two distinct ratios for the conventional reinforcement were adopted, one for the slabs' series with plain concrete and another for the steel fibre reinforced self-compacting concrete (SFRSCC) slabs' series, but the reinforcement ratio in the critical punching region was the same in both configurations $(\rho=0.88 \%)$, Figure 2.

Eight different concrete compositions were grouped in two strength classes with compressive strengths of 50 and $70 \mathrm{MPa}$, in order to assess its influence in the punching resistance. For similar purposes, four distinct fibre contents, $0,60,75$ and $90 \mathrm{~kg} / \mathrm{m}^{3}$ were adopted. The selected hooked ends steel fibres had the following mechanical and geometric characteristics: $37 \mathrm{~mm}$ of length $\left(l_{f}\right)$, diameter of $0.55 \mathrm{~mm}\left(d_{f}\right), 67$ of aspect ratio $\left(l_{f} / d_{f}\right)$, and tensile strength of about $1100 \mathrm{MPa}$. Hereinafter, to easily differ the distinct slabs, the acronym $C_{f} X f_{c} Y$ will be used, where $X$ is the theoretical content of fibres (per concrete cubic meter) and $Y$ the target concrete compressive strength (in $\mathrm{MPa}$ ). For example, the slab $C_{f} 60 f_{c} 70$ indicates a concrete slab planned to have a fibre content of $60 \mathrm{~kg} / \mathrm{m}^{3}$ and a compressive strength of $70 \mathrm{MPa}$. Additionally, for each fibre reinforced slab, nine prismatic specimens with $150 \times 150 \times 600 \mathrm{~mm}^{3}$ were cast and cured in the same conditions of the corresponding slab in order to assess the residual flexural tensile strengths. The latter were assessed by three-point bending tests carried out according the recommendation of EN 14651:2005 [27].

Table 1 presents the composition of the concrete batches. There are some differences in the compositions, since it was necessary to have into consideration the interference of the fibres in the skeleton arrangement of the aggregates, without compromising the requisites of self-compactability and occurrence of segregation for the constituents in all mixes. The mix design has followed the strategy adopted by Barros et al. [28]. The mechanical properties of the steel bars were determined by executing experimental tests according the recommendation of ISO 15630-1 [29]. Table 2 presents the average results of the uniaxial tensile tests performed on five bar specimens. 
Figure 3 illustrates the test setup, where the supports location and the load actuator position can be seen. The load actuator had a bearing capacity of $1000 \mathrm{kN}$. The punching test was carried out under a closed-loop displacement control with a displacement rate of $0.05 \mathrm{~mm} / \mathrm{min}$ measured at the centre of the slab. The supports consisted in twelve Dywidag ${ }^{\circledR}$ steel bars of $35 \mathrm{~mm}$ diameter. These bars passed through the holes of the testing slab and the holes of a stiff reaction floor. On the top face of the holes executed in the testing slab, plates of $200 \times 200 \times 50 \mathrm{~mm}^{3}$ were used to anchor the extremities of the Dywidag ${ }^{\circledR}$ bars.

Before discussing the experimental results, previously, there are some considerations that should be addressed for a better comprehension of these results, as well as the mechanical properties for the tested concrete slabs to be adopted in the numerical simulations. The concrete compositions and casting of the slabs were executed in a ready mix-plant, in which the introduction of concrete constituents in the mixer was fully automated. Along with other constituents, the fibres were directed towards the mixer in a treadmill. However, in some slabs fibres fell down from the treadmill during the path up to the mixer, resulting in a content of fibres smaller than the expected. Therefore, in order to verify the real fibre content $\left(C_{f}\right)$, a strategy similar to the one used by Barros and Antunes [21] was adopted. This strategy consists in obtaining the number of fibres at the fracture surface $\left(N_{f}\right)$ of the three-point notched beam bending tests. Having into account the $N_{f}$ obtained from the three-point bending tests, and adopting the fibre orientation factors proposed by Abrishambaf et al. [30] for SFRSCC with similar rheological properties and type of fibres, the $C_{f}$ for the tested slabs could be inferred according to the expression proposed by Krenchel [31]. Table 3 includes the fibre content in the tested slabs according to this methodology. In general, the real fibre content was lower than the expected one. The $C_{f} 60 f_{c} 50$ and $C_{f} 75 f_{c} 50$ series seem to have a significantly lower fibre content than the expected value, respectively, 50\% and $57 \%$. On the other hand, in the $C_{f} 75 f_{c} 70$ composition the determined fibre content is nearby $15 \%$ higher than the target value. These occurrences will help to explain and corroborate further ahead some discrepancies on the slab's behaviour in the punching tests, as well as justify some of the observed failure mechanisms.

\subsection{Experimental results}

Figures $4 \mathrm{a}$ and $4 \mathrm{~b}$ show the load - deflection relationships, $P-\delta$, for the series with a compressive strength of 50 and $70 \mathrm{MPa}$, respectively. The deflection was assessed at the centre of the slabs. Table 4 resumes the relevant results withdrawn from the $P-\delta$ curves, where $P_{\max }$ is the maximum applied load and $\delta_{P_{\max }}$ is its corresponding deflection. $P_{\max }^{S F R C C}$ is the maximum load of a SFRSCC slab and $P_{\max }^{R E F}$ of its correspondent reference slab; $\delta_{\max }^{S F R S C C}$ and $\delta_{\max }^{R E F}$ are the deflections at $P_{\max }$ of a SFRSCC slab and its correspondent reference slab. Moreover, this table also includes the 
failure mode observed for each slab. In general, with the increase of the fibre content an increase of both $P_{\max }$ and $\delta_{P_{\max }}$ was observed. Thus the addition of fibres contributed to an increase of the bearing capacity of the current structural system, as well as to the increase of the deflection at $\delta_{P_{\max }}$, i.e. toughness. The fibres proven to be more efficient on increasing the toughness rather than the loading bearing capacity. This was due mainly by avoiding the punching failure mechanism, as fibres contributed to the increase of the shear strength (as only specific reinforcement), while the conventional rebars provided the main flexural reinforcement.

Due to a lower content of fibres than the expected, in the $C_{f} 60 f_{c} 50$ and $C_{f} 75 f_{c} 50$ slabs (around $30 \mathrm{~kg} / \mathrm{m}^{3}$, see Table 3), they have exhibited a punching failure mode, likewise the correspondent reference slab, Table 4. Notice that the reference slabs only had flexural reinforcement and for that reason it was expected to fail by punching. The results in Table 4 show that for the slabs with a compressive strength of $50 \mathrm{MPa}$, the increase in terms of maximum load was only significant $(12 \%)$ in the $C_{f} 90 f_{c} 50$, which has failed in bending. Meanwhile, for the series with a compressive strength of $70 \mathrm{MPa}$, all the slabs reinforced with fibres have shown a higher increase in terms of maximum load, ranging from 16 to $24 \%$. Therefore, from the analysis of the results can be pointed out that up to a fibre content of $30 \mathrm{~kg} / \mathrm{m}^{3}$, there is not an increase of the slabs' bearing capacity and is not possible to avoid the brittle punching shear failure. In terms of deflection at maximum load, $\delta_{P_{\max }}$, the increase of the $\delta_{\max }^{S F R C C} / \delta_{\max }^{R E F}$ ratio, as expected, was only significant in the slabs failing in bending, with an increase of $72 \%$ in $C_{f} 90 f_{c} 50$ slab, and more than $100 \%$ in $C_{f} 90 f_{c} 70$. The unexpected low content of fibres present in the $C_{f} 60 f_{c} 50$ and $C_{f} 75 f_{c} 50$ slabs (about $30 \mathrm{~kg} / \mathrm{m}^{3}$ ) has only contributed to a marginal increase of the deflection at punching failure load, nearby 4 to $6 \%$. Thus only for fibre contents higher than $30 \mathrm{~kg} / \mathrm{m}^{3}$ the deflection $\delta_{\text {max }}^{\text {SFRC }}$ was significant.

The post-cracking residual flexural tensile strength parameters $\left(f_{R, i}\right)$ of the distinct SFRSCC were determined with prismatic specimens according the recommendations of EN 14651:2005 [27]. From each three-point notched beam bending test (3PBT) it was obtained a relationship between the applied force and the crack mouth opening displacement (CMOD). By evaluating the force at CMOD values of $0.5,1.5,2.5$ and $3.5 \mathrm{~mm}$, the $f_{R, i}$ values were determined by applying the following equation:

$$
f_{R, i}=\frac{3 \cdot F_{i} \cdot L}{2 \cdot b \cdot h_{s p}{ }^{2}}
$$


where $b(=150 \mathrm{~mm})$ and $L(=500 \mathrm{~mm})$ are the width and the span of the specimen, respectively. $h_{s p}$ is the distance between the tip of the notch and the top of the cross section. In an attempt of assuring an unique crack and avoiding coalescence of multiple macro-cracks along the notched plane in the three point SFRSCC beam bending tests, the depth of the notch was increased with the content of fibres $\left(25,42.5\right.$ and $60 \mathrm{~mm}$ for the $C_{f}=60,75$ and $90 \mathrm{~kg} / \mathrm{m}^{3}$, respectively), as indicated in Table 5. Due to technical issues only seven specimens were successfully tested in both $C_{f} 75 f_{c} 70$ and $C_{f} 90 f_{c} 70$ series. Table 5 includes the average values of $f_{R, i}$, the values in round brackets correspond to the computed coefficient of variation. In general, relatively high values of $f_{R, i}$ were obtained, the two exceptions were the $C_{f} 60 f_{c} 50$ and $C_{f} 75 f_{c} 50$ series, which was in accordance with the observed low fibre content in those series, as previously discussed. Moreover, in spite of the high coefficients of variation observed, it was within the expectable range for this kind of material.

Figure 5 plots the relationships between the maximum load of each slab, $P_{\max }$, and the $f_{R, i}$. Additionally, linear regression curves between $P_{\max }$, and $f_{R, i}$ for each class strength series were also included. Good correlation factors between $P_{\max }$, and the $f_{R, i}$ were found, evidencing a linear trend between the residual flexural parameters and the maximum load of the tested slabs. This also justifies the punching failure mechanism observed in some steel fibre reinforced slabs, i.e. $C_{f} 60 f_{c} 50$ and $C_{f} 75 f_{c} 50$, since these series unveiled the lower residual flexural strengths, which ranged between 1.96 and $5.92 \mathrm{MPa}$, and from 2.16 to $6.35 \mathrm{MPa}$, respectively.

\section{NUMERICAL SIMULATIONS OF THE PUNCHING TESTS}

\subsection{Numerical model}

The Reissner-Mindlin theory was selected to simulate the material nonlinear behaviour of thin FRC panels, where outof-plane shear deformation might be appreciable [32]. The damage due to crack formation and propagation was simulated by discretizing the thickness of the shell into several layers. Fibres bridging micro-cracks contribute to the formation of diffuse crack patterns, since they offer resistance to the coalescence of those micro-cracks into macro-cracks. Therefore, smeared crack constitutive models are, conceptually, more appropriate than discrete crack models in the simulation of crack propagation in FRC structures, mainly, in those with a high number of redundant supports [33]. In the present section only the innovative aspects implemented in the multi-fixed smeared crack model for the modelling of the punching shear behaviour will be described. This model is implemented in the FEMIX 4.0 software, and its full description can be found elsewhere [33]. For the case of cracked concrete the constitutive law is defined by the following equation: 


$$
\left[\begin{array}{c}
\Delta \underline{\sigma}_{m f} \\
\underline{\sigma}_{s}
\end{array}\right]=\left[\begin{array}{cc}
\underline{D}_{m f}^{c r c o} & \underline{0} \\
\underline{0} & \underline{D}_{s}^{c r c o}
\end{array}\right]\left[\begin{array}{c}
\Delta \underline{\varepsilon}_{m f} \\
\underline{\varepsilon}_{s}
\end{array}\right]
$$

where $\Delta \underline{\sigma}_{m f}$ and $\Delta \underline{\varepsilon}_{m f}$ are the vectors corresponding to the in-plane stress and strain increment components, respectively (membrane and bending components); whereas $\underline{\sigma}_{s}$ and $\underline{\varepsilon}_{s}$ are the vectors corresponding to the out-of-plane shear stress and shear strain components, respectively. In Equation (2), $\underline{D}_{m f}^{c r c o}$ is the in-plane cracked concrete constitutive matrix [34].

Figure 6 defines the fracture mode I modulus, $D_{I}^{c r}$, where $\alpha_{i}$ and $\xi_{i}$ are the parameters that define the shape of the crack's normal stress vs. normal strain diagram. The ultimate crack strain $\left(\varepsilon_{n, u}^{c r}\right)$ is defined as a function of $\alpha_{i}$ and $\xi_{i}$ parameters, fracture energy $\left(G_{f}^{I}\right)$, tensile strength $\left(f_{c t}=\sigma_{n, I}^{c r}\right)$ and crack bandwidth $\left(l_{b}\right)$ [34]. Regarding fracture mode II, in-plane shear mode, a decrease of the shear retention factor, $\beta$, with the increase of the crack strain was adopted [34, 35]. On the other hand, Figure 7 depicts the diagram used to simulate the out-of-plane shear softening behaviour.

\subsection{Two-dimensional layered geometry model}

To simulate the punching tests, only one quarter of the slab was modelled, due to its double symmetry. Figure 8 depicts both the supports adopted on the experimental setup as well as the ones used to ensure the symmetry conditions, which are represented by blue markers. The three supports outside the symmetry axis (represented by red markers in Figure 8) have only one fixed degree of freedom, in the $z z$ direction, i.e. perpendicular to the $x y$ plane that corresponds to the middle surface of the slab. On the other hand, the blue markers located on two edges of the quarter's slab correspond to the supports introduced to enforce the double symmetry conditions. The load was applied at the bottom left corner of the mesh, i.e. centre point of the slab, under displacement control by using the arc-length method.

The adopted mesh is comprised by 196 Reissner-Mindlin 8-noded shell elements (Figure 8a). A Gauss-Legendre integration scheme of $2 \times 2$ was adopted. Each shell element was discretized into fifteen layers with a total thickness of $150 \mathrm{~mm}$. Within these layers, one is used to model the steel bars non-linear behaviour, whereas the other ones are used to model the fracture process of the SFRSCC, namely, four for the cover concrete on the top of the slabs and ten for the remaining concrete under the steel bars. Moreover, two simultaneous smeared cracks can arise at each integration point. In Figure 2 it is possible to notice that there are three zones of distinct longitudinal reinforcement ratios. These three zones were taken into account in the numerical model by adopting a distinct layer discretization for each zone (Figure 8a). Thus, Zone 1 is the one with the highest level of reinforcement, at the centre of the slab; Zone 2 is the one of intermediate level 
of reinforcement; and the Zone 3 presents the lower level of reinforcement. Note that in Zone 3, for the SFRSCC slabs there is no conventional reinforcement, so, in that zone, there are 15 layers with the same thickness, $10 \mathrm{~mm}$. Table 6 includes both the thickness and corresponding number of layers in each shell element at the distinct reinforcement zones. The layers are enumerated in the positive direction of $z$ axis, i.e. from bottom to top slab surface.

\subsection{Parameters for the constitutive material models}

The mechanical properties of the steel rebars were directly derived from tensile tests, which were previously presented. The tensile behaviour of the steel was modelled with a quadrilinear relationship, similar to the one presented in Figure 6 . However, the post-peak parameters translate the steel behaviour in the yielding stage. The parameters for the quadrilinear diagram are presented in Table 7. Note that $G_{f}^{I}$ is a fictitious parameter that represents the energy absorption capacity of the steel. Moreover, for the Poisson's ratio (v) was adopted a null value, 209.49 GPa for the Young modulus ( $\left.E_{S}\right)$ and 467.01 MPa for both the compressive $\left(f_{c}\right)$ and tensile yielding $\left(f_{s y}\right)$ stresses.

Table 8 presents the values of parameters used to define the concrete's constitutive post-cracking law depicted in Figure 6. For the elastic properties, a Poisson's ratio of 0.15 and a Young modulus of $37.20 \mathrm{GPa}$ were adopted. The post-cracking behaviour considered for the $C_{f} O f_{c} 50$ and $C_{f} O f_{c} 70$ series, i.e. plain concrete, was obtained according to the recommendations proposed by the CEB-FIP Model Code 2010 [36]. On the other hand, the parameter values used for the SFRSCC post-cracking behaviour were obtained by inverse analysis by fitting the numerical response to the experimental curves obtained in the punching tests. Details of this procedure can be found elsewhere [37].

It is also important to refer that for both slabs $C_{f} 60 f_{c} 50$ and $C_{f} 75 f_{c} 50$, the concrete layers were ascribed with distinct tensile post-cracking behaviour as resumed in Table 8. As previously detailed, these slabs had some issues during their casting, in particular with the effective fibre content introduced into the mixture. Moreover, to take into account a heterogeneous fibre distribution along the slab's depth, which could be ascribed to fibre segregation problems, distinct values for the fracture energy were attributed to the layers. Nevertheless, the parameters $\xi_{i}$ and $\alpha_{i}$ were kept constant, therefore the shape of the post-cracking diagram was similar within the slab's distinct layers. Three cylindrical cores were performed in each $C_{f} 60 f_{c} 50$ and $C_{f} 75 f_{c} 50$ slabs in order to assess the variation of fibre content along the slab's height. The fracture energy variation along the slab's height was defined according to the fibre content variation. The fibre content followed up a parabolic trend from the bottom to the top layer. A fracture energy decrease from 1.25 to $0.08 \mathrm{~N} / \mathrm{mm}$ with the same 
trend of the fibre content was ascribed from the bottom, layer n. 1 (compressed zone), to the top layer, layer n. 15 (tensioned zone), respectively (Figure $8 \mathrm{~b}$ and Table 8). Since the real fibre content and average compressive strength of $C_{f} 75 f_{c} 50$ slab were similar to those of $C_{f} 60 f_{c} 50$ slab, the same values for the constitutive post-cracking relationship were adopted in the simulation of these two slabs. Notice also that the value of the fracture energy for the slab $C_{f} 75 f_{c} 70$ (with an expected fibre content of $75 \mathrm{~kg} / \mathrm{m}^{3}$ ) is higher than the fracture energy for the slab $C_{f} 90 f_{c} 70$ (with an expected fibre content of $90 \mathrm{~kg} / \mathrm{m}^{3}$ ). This could be explained by the real fibre content present in each slab, which was lower in the slab $C_{f} 90 f_{c} 70$, see Table 3.

\subsection{Comparison of the numerical and experimental results}

Figures 9 and 10 depict, for each slab, both the numerical and experimental curves. The numerical simulations are in good accordance with the experimental curves. In general, the observed failure modes on the experimental tests were successfully predicted. Concerning the numerical simulation of the $C_{f} O f_{c} 50$ slab (Figure $9 \mathrm{a}$ ), it was predicted the punching shear failure, however the displacement for which this type of failure occurs was slightly overestimated, approximately $10 \%$. On the other hand, for the $C_{f} 60 f_{c} 50$ and $C_{f} 75 f_{c} 50$ slabs (Figure 9b) the load decay observed experimentally due to punching was not captured numerically due to difficulties on the convergence process of the numerical simulations of both slabs. However, the deformational response was predicted with high accuracy, and since convergence was not possible to assure precisely at the deflection level coinciding with the punching failure observed experimentally, it is presumed that the model is almost in the situation of capturing this type of failure mode. Finally, in the $C_{f} 90 f_{c} 50$ slab (Figure 9c), both the experimental and numerical curves are almost coincident in all their development. Neither of them show a punching failure, due to the high fibre content used in this series.

On the other hand, for the series with a compressive strength of $70 \mathrm{MPa}$, the simulations were even more accurate. As it can be seen in Figure 10, all the simulations were almost coincident with the experimental curves. Once again, for the slab $C_{f} O f_{c} 70$ (Figure 10a) the punching failure was not precisely captured, again due to convergence problems, however, the last converged point of the numerical curve is practically coincident with the experimental punching failure. For both $C_{f} 60 f_{c} 70$ (Figure 10b) and $C_{f} 75 f_{c} 70$ (Figure 10c), the experimental curves do not exhibited a punching failure and neither did the numerical ones. Moreover, they were almost coincident on all their extent. The numerical curve regarding the slab $C_{f} 90 f_{c} 70$ (Figure 10d) showed that the experimental and numerical curves were almost coincident and the bending/punching failure was numerically predicted for the same displacement and level of loading. 


\section{PARAMETRIC ANALYSIS}

As previously stated, due to some issues that occurred during the casting procedure, some slabs exhibited a lower fibre content than it was expected. Therefore, it could not be fully ascertained for what level of fibre content and concrete strength the punching shear failure could be avoided. Moreover, the length of the selected fibre was relatively short $(37 \mathrm{~mm})$ and its aspect ratio not so high (67), thus the selected fibre may not be the most effective one. It is well established that a higher aspect ratio will lead to a higher number of fibres in concrete bulk [37], which increases the probability of having higher number of fibres bridging active cracks. Hence, in this section will be conducted a parametric study to assess the influence of the fracture energy parameter and the shape of the second branch of the post-cracking stress strain diagram on the deformational response of the slabs. The fracture energy will be obtained according to experimental data for fibres with a higher aspect ratio [33]. Having in mind that the numerical model was previously calibrated and shown a good accuracy on predicting the experimental results, the outcome of the numerical simulations comprised in the parametric study may render a relatively accurate estimation of the behaviour of slabs reinforced with fibres of a higher aspect ratio and distinct fibre contents.

\subsection{Influence of the fracture energy}

The influence of the fracture energy on the deformational response of the slab was ascertained. For this purpose, the fracture energy of concretes corresponding to the fibre contents, $C_{f}$, adopted in the experimental programme, i.e. 60,75 and $90 \mathrm{~kg} / \mathrm{m}^{3}$, were assessed through an analytical expression proposed by Barros and Figueiras [33]. The latter correlates the fracture energy of a fibre reinforced concrete with the weight percentage of fibres (60/.80). This fibre has a length of $60 \mathrm{~mm}$, diameter of $0.8 \mathrm{~mm}$ and an aspect ratio of 75 . Thus, the fracture energy of fibre reinforced concrete, $G_{f}^{I}$, was computed as follows:

$$
\frac{G_{f}^{I}}{G_{f 0}}=1.0+13.159 W_{f}^{1.827}
$$

where $G_{f 0}$ is the fracture energy of the corresponding plain concrete and $W_{f}$ is the weight percentage of fibres in the mixture. According to the CEB-FIB Model Code 2010 [36], for a plain concrete with an average compressive strength of $50 \mathrm{MPa}$, the value of fracture energy is $0.147 \mathrm{~N} / \mathrm{mm}$, whilst for a plain concrete with a compressive strength of $70 \mathrm{MPa}$, the fracture energy is $0.156 \mathrm{~N} / \mathrm{mm}$. Table 9 presents the estimated fracture energy for fibre reinforced concrete compositions with three distinct fibre contents, i.e. 60,75 and $90 \mathrm{~kg} / \mathrm{m}^{3}$, and using a fibre with a higher aspect ratio (75). 
Hence, the numerical simulations were carried out using the parameters of the post-cracking stress - strain diagram used for the $C_{f} 60 f_{c} 50$ and $C_{f} 60 f_{c} 70$ series, changing only the fracture energy value by the ones computed with Equation (3) and presented in Table 9. Figures 11a and 11b show the numerical simulations carried out for the series with a compressive strength of 50 and $70 \mathrm{MPa}$, respectively, assuming the new estimated fracture energy values presented in Table 9 computed for the new hooked end steel fibres (60/.80). As it was expected, the load carrying capacity and toughness of the slabs increased with the increase of the fracture energy, regardless of the compressive strength adopted in this study. Table 10 presents the ratio between the maximum numerical load $\left(P_{\max }\right)$ and the maximum experimental load ( $\left.P_{\max }^{E x p}\right)$, the ratio between the numerical displacement at maximum load $\left(\delta_{\max }\right)$ and the correspondent experimental one $\left(\delta_{\max }^{E x p}\right)$, and the ratio between the numerical load for a crack width of $0.3 \mathrm{~mm}\left(P_{0.3 \mathrm{~mm}}\right)$ and the correspondent experimental one $\left(P_{0.3 m m}^{E x p}\right)$. These values were obtained considering the use of 60,75 and $90 \mathrm{~kg} / \mathrm{m}^{3}$ of fibres $60 / .80$. Note that the load $P_{0.3 \mathrm{~mm}}$ was obtained for the numerical load step in which a crack reached the $0.3 \mathrm{~mm}$ width. In the present case this occurred for the integration point nearer the load application and in the top layer of the Mindlin shell element. Moreover, since there was no experimental information regarding the crack opening, for the series Exp - $C_{f} 60$, it was used the information from the numerical curve obtained by inverse analysis in section 4.2. The crack width was obtained by multiplying the crack normal strain component by the crack band width.

In what concerns to numerical results assuming a fibre content of $60 \mathrm{~kg} / \mathrm{m}^{3}$ with a fibre length of $60 \mathrm{~mm}$ and an aspect ratio of 75 , when compared to the experimental results $\left(60 \mathrm{~kg} / \mathrm{m}^{3}\right.$ with a fibre length of $37 \mathrm{~mm}$ and an aspect ratio of 67$)$, it is visible an increase of both the maximum load and load at the onset of a crack opening of $0.3 \mathrm{~mm}$. This increase was more significant for the series with a compressive strength of $70 \mathrm{MPa}$, which was about $26 \%$. Thus, the use of a fibre with a higher aspect ratio would assure higher load carrying capacity for this flat slabs structural system at both serviceability and ultimate stages. It was also noticed for a fibre content of $90 \mathrm{~kg} / \mathrm{m}^{3}$ an increase in the maximum load about 86 and $69 \%$, respectively, for the series with 50 and $70 \mathrm{MPa}$. The increase of the displacement at the maximum load was also significant for the series $C_{f} 90$, and was near 79 and 47\%, respectively, for the series with 50 and $70 \mathrm{MPa}$.

\subsection{Influence of the shape of the material law}

The influence of the slope of second branch of the stress - strain diagram on the response of the slabs was assessed. For this purpose, it is considered the same fracture energy for all the simulations carried out, but for the stress of the second 
post-peak point for the following three distinct levels of $0.50 \mathrm{f}_{\mathrm{ctm}}, 1.00 \mathrm{f}_{\mathrm{ctm}}$ and $1.25 \mathrm{f}_{\mathrm{ctm}}$ were considered, where $\mathrm{f}_{\mathrm{ctm}} \mathrm{was}$ the average concrete tensile strength. The post-cracked stress-strain diagrams used in the numerical simulations are depicted in Figures $12 \mathrm{a}$ and $12 \mathrm{~b}$ for the 50 and $70 \mathrm{MPa}$ series, respectively.

The values of the fracture energy considered correspond to the ones computed for the slabs $C_{f} 60 f_{c} 50$ and $C_{f} 60 f_{c} 70$ (Table 7). Figures $13 \mathrm{a}$ and $13 \mathrm{~b}$ depict the results of the simulations. The load carrying capacity of the slabs increased with the increase of the stress value of the point defining the shape of the second branch of the trilinear diagram. Table 11 includes the $P_{\max } / P_{\max }^{E x p}, \delta_{\max } / \delta_{\max }^{E x p}$ and $P_{0.3 m m} / P_{0.3 m m}^{E x p}$ ratios obtained for the three stress values adopted for the second point of the trilinear diagram, respectively, for the $f_{c m}=50$ and $70 \mathrm{MPa}$ series. It can be observed that the maximum load was higher than the one observed in the experimental results using the fibres with a lower aspect ratio. For the $50 \mathrm{MPa}$ series the increase of the load was in-between $8 \%$ and $12 \%$, while for the $70 \mathrm{MPa}$ series this increase ranged between $6 \%$ and 21\%. Table 11 includes also the ratio between the numerical load for which was attained a crack width opening of 0.3 $\mathrm{mm}$ and the correspondent experimental load. For the same values of $G_{f}$ and by modifying the inclination of the second branch, the load at a crack opening width of $0.3 \mathrm{~mm}$ was 16 to $31 \%$ higher than the correspondent one for the experimental curve, for the series with a compressive strength of $50 \mathrm{MPa}$. On the other hand, for the higher strength concrete (70 MPa) a smaller increase ranging $2 \%$ and $18 \%$ was observed for the load at a crack opening width of $0.3 \mathrm{~mm}$.

It is also important to refer that the influence of shifting horizontally the second post-peak point of the stress-strain diagram, i.e. changing the value of the $\xi_{2}$ parameter (Figure 6), was also studied. Considering the new horizontal position as $1.40 \xi_{2}$ and $2.00 \xi_{2}$ (for the $50 \mathrm{MPa}$ series), and $0.875 \xi_{2}$ and $1.125 \xi_{2}$ (for the $70 \mathrm{MPa}$ series) of the initial $\xi_{2}$ parameter no significant differences on the slab's response were observed, since all the numerical curves were almost coincident. This could be explained by the fact that for the attained slab's deflection level, the strain at the integration point did not reach the strain corresponding to the second post-peak point of the stress-strain diagram. Moreover, this could also suggest that the slab's flexural residual capacity is still far from being reached.

\section{CONCLUSIONS}

In this work the results of punching shear tests carried out on flat slabs with a hybrid reinforcement (rebar + discrete fibres) are presented and discussed. Eight half scaled slabs, reinforced with distinct fibre contents, namely, 0, 60, 75 and $90 \mathrm{~kg} / \mathrm{m}^{3}$, and different compressive strengths (50 and $70 \mathrm{MPa}$ ) were tested. The experimental results were numerically 
modelled under the FEM framework. Moreover, a total of 54 three-point bending tests were carried out to assess the postcracking flexural tensile strength.

In the experimental tests, and due to deficiencies on the automatic procedure of introducing the fibres into the mixer, the slabs reinforced with 60 and $75 \mathrm{~kg} / \mathrm{m}^{3}$ and a compressive strength of $50 \mathrm{MPa}$ showed relative low content of fibres (around $30 \mathrm{~kg} / \mathrm{m}^{3}$ ). Therefore, both of them have failed in punching like the corresponding reference slabs (without fibre reinforcement). For the slabs reinforced with the highest fibre content (i.e $90 \mathrm{~kg} / \mathrm{m}^{3}$ ) an increase from 12 to $24 \%$ in terms of maximum load was observed, followed by a flexural failure mode. The increase in the maximum deflection, $\delta_{P_{\max }}$, was only significant in the slabs with the highest fibre content, with an increase between 72 and $102 \%$.

The load-deflection curves obtained in the numerical simulations are in good accordance with the experimental ones. In general, the type of failure mode observed on the experimental tests was also successfully predicted. A parametric study was also carried out in order to assess the influence on the slab's mechanical response of the fracture energy and the shape of the first branch of the diagram that defines the crack opening process. The values of the fracture energy were estimated having in consideration the use of a fibre with a higher aspect ratio. It was found out that the higher aspect ratio lead to higher fracture energies, and consequently, the slab presented a higher load carrying capacity without occurring the punching shear failure. In terms of the shape of the first branch of the crack constitutive law, it was observed that when the first post-cracking stress point is $1.25 \mathrm{f}_{\mathrm{ctm}}$ (tensile strain hardening), a significant increase occurs on the load carrying capacity for both serviceability and ultimate limit states.

\section{ACKNOWLEDGEMENTS}

This work is supported by FEDER funds through the Operational Program for Competitiveness Factors - COMPETE and

National Funds through FCT - Portuguese Foundation for Science and Technology under the project "SlabSys - HFRC Flat slabs for multi-storey buildings using hybrid reinforced self-compacting concrete: an innovative structural system" PTDC/ECM/120394/2010.

\section{REFERENCES}

[1] Wight, J.K.; MacGeregor, J.G. Reinforced Concrete: Mechanics and Design. Fifth Edition, New Jersey: Prentice Hall, 
[2] Delahay, P.E.J.; Christopher, P.E.B. Current trends in economical concrete construction, Part one: Floor framing and lateral systems. Structure Magazine, pp. 19-21, July 2007.

[3] Maya, L. F.; Fernández Ruiz, M.; Muttoni, A.; Foster, S. J. Punching shear strength of steel fibre reinforced concrete slabs. Engineering Structures, 40(0), pp. 83-94, 2012.

[4] Muttoni A. Punching Shear Strength of Reinforced Concrete Slabs without Transverse Reinforcement. ACI Structural Journal, 105(4), pp. 440-450, 2008.

[5] Ozden, S.; Ersoy, U.; Ozturan, T., Punching shear tests of normal- and high-strength concrete flat plates. Canadian Journal of Civil Engineering, 2006. 33(11): p. 1389-1400.

[6] Melo, G.S.; Coelho, A.E.G.; Oliveira, D.R.C. Reinforced concrete flat slabs with inclined stirrups as shear reinforcement. International Workshop on Punching Shear Capacity of RC Slabs - Proceedings. TRITA-BKN, Bulletin 57, pp. 155-162, 2000.

[7] Tan, K-H.; Paramasivam, P. Punching shear strength of steel fiber reinforced concrete slabs. Journal of Materials in Civil Engineering, 6(2), pp. 240-253, May 1994.

[8] Prisco, M.; Felicetti, R. Some results on punching shear in plain and fibre-reinforced micro-concrete slabs. Magazine of Concrete Research, 49(180), pp. 201-219, September 1997.

[9] Nguyen-Minh, L.; Rovňák, M.; Tran-Quoc, T.; Nguyenkim, K. Punching Shear Resistance of Steel Fiber Reinforced Concrete Flat Slabs. Procedia Engineering 14(0): 1830-1837, 2011.

[10] Moraes-Neto, B.N.; Barros, J.A.O.; Melo, G.S.S.A. A model for the prediction of the punching resistance of steel fibre reinforced concrete slabs centrically loaded. Construction and Building Materials Journal, 46, pp. 211-223, 2013. [11] Soutsos, M. N.; Le, T. T.; Lampropoulos, A. P. Flexural performance of fibre reinforced concrete made with steel and synthetic fibres. Construction and Building Materials 36(0): 704-710, 2012.

[12] Banthia, N. in: J.I. Daniel, S.P. Shah (Eds.), ACI SP-142. Fiber Reinforced Concrete ACI, pp. 91-120, 1994.

[13] di Prisco, M.; Plizzari, G.; Vandewalle, L. Fibre reinforced concrete: new design perspectives. Materials and Structures 42(9): 1261-1281, 2009.

[14] Balaguru, P.N.; Shah, S.P. Fiber Reinforced Cement Composites, McGraw Hill, 1992.

[15] Michels, J.; Waldmann, D.; Maas, S.; Zürbes, A. Steel fibers as only reinforcement for flat slab construction Experimental investigation and design. Construction and Building Materials 26(1): 145-155, 2012.

[16] Barros, J.A.O.; Figueiras, J.A. Experimental behaviour of fiber concrete slabs on soil. Mechanics of Cohesive Frictional Materials 3(3): 277-290, 1998.

[17] X. Destrée. Steel-fibre-only reinforced concrete in free suspended elevated slabs. Concrete Engineering International. 13(1), pp. 47-49, 2009. 
[18] X. Destrée. Structural application of steel fibre as principal reinforcing: conditions - Design examples, in RILEM PRO15, Fibre Reinforced Concretes (FRC) BEFIB 2000, 2000.

[19] X. Destrée. Steel-fibre-reinforced pile-supported slabs. Concrete (London). 41(4), pp. 26-27, 2007.

[20] Swamy, R.N. FRC for sustainable infrastructure regeneration and rehabilitation In Fibre-Reinforced Concretes (FRC) BEFIB 2000: 3-18, Lyon, France, 2000.

[21] Barros, J.A.O.; Antunes, J.A.B. Experimental characterization of the flexural behaviour of steel fibre reinforced concrete according to RILEM TC 162-TDF recommendations. RILEM TC 162 TDF Workshop, 77-89, March, 2003.

[22] Babut, R. Structural investigation of steel fibre reinforced concrete. Fracture mechanics and structural aspects of concrete 31: 29-44. Delft, Netherlands, 1986.

[23] Stähli P.; Custer R.; van Mier J. On flow properties, fibre distribution, fibre orientation and flexural behaviour of FRC. Materials and Structures, 41(1), 189-196, 2008.

[24] Harajli, M.H.; Maalouf, D.; Khatib, H. Effect of fibers on the punching shear strength of slab-column connections. Cement and Concrete Composites 17(2): 161-170, 1995.

[25] Choi, K.K.; Reda Taha, M.M.; Park, H.G.; Maji, A.K. Punching shear strength of interior concrete slab-column connections reinforced with steel fibers. Cement and Concrete Composites 29(5): 409-420, 2007.

[26] Ragab, K.S. Study Punching Shear of Steel Fiber Reinforced Self Compacting Concrete Slabs by Nonlinear Analysis. International Journal of Civil Science and Engineering. 7: 106-118, 2013.

[27] EN 14651:2005. Test method for metallic fibre concrete - Measuring the flexural tensile strength (limit of proportionality (LOP), residual). CEN - European Committee for Standardization, 2007.

[28] Barros, J.A.O.; Pereira, E.B.; Santos, S.P.F. Lightweight panels of steel fiber reinforced self-compacting concrete. ASCE Materials in Civil Engineering Journal, 19(4), pp. 295-304, 2007. http://hdl.handle.net/1822/9246

[29] ISO 15630-1. Steel for the reinforcement and prestressing of concrete - Test methods - Part 1: Reinforcing bars, wire rod and wire. International Standard, First edition, April 2002.

[30] Abrishambaf, A.; Barros, J.A.O.; Cunha, V.M.C.F. Relation between fibre distribution and post-cracking behaviour in steel fibre reinforced self-compacting concrete panels, Cement and Concrete Research 51, pp. 57-66, 2013.

[31] Krenchel H. (1975). Fibre spacing and specific fibre surface. In RILEM Symposium: Fibre Reinforced Cement and Concrete, Volume 1, pp. 69-79. Horneby, Lencaster.

[32] Reissner, E., The effect of transverse shear deformation on the bending elastic plates. Journal of Applied Mechanics, 12, pp. 69-76, 1945.

[33] Barros, J.A.O.; Figueiras, J.A. Nonlinear analysis of steel fibre reinforced concrete slabs on grade. Computers \& Structures Journal, 79(1), pp. 97-106, January 2001. 
[34] Ventura-Gouveia, A.; Barros, J.A.O; Azevedo, A.F.M.; Crack constitutive model for the prediction of punching failure modes of fiber reinforced concrete laminar structures, Computers \& Concrete, 8(6), 735-755, 2011.

[35] Rots, J.G.; de Borst, R. Analysis of mixed-mode fracture in concrete. Journal of Engineering Mechanics, ASCE, 113(11), pp. 1739-1758, 1987.

[36] CEB-FIB Model Code 2010 CEB-FIB Model Code 2010 - Final draft. Thomas Thelford, Lausanne, Switzerland, 2010.

[37] Barros, J.A.O.; Cunha, V.M.C.F.; Ribeiro, A.F.; Antunes, J.A.B. Post-Cracking Behaviour of Steel Fibre Reinforced Concrete. Materials and Structures Journal, RILEM, 38(275), pp. 47-56, 2005. 


\section{LIST OF TABLE CAPTIONS}

Table 1. Self-compacting concrete mixes $\left[\right.$ per $\left.\mathrm{m}^{3}\right]$.

Table 2. Average values of the tensile properties of the steel bars used in the flexural reinforcement of the slabs.

Table 3. Content of fibres in the notched plane of SFRSCC beam bending tests, and the determined content of fibres.

Table 4. Main results obtained in the punching tests.

Table 5. Residual flexural strengths, $f_{\mathrm{R}, \mathrm{i}}$, obtained in the three-point bending tests.

Table 6. Thickness of the layers in the shell element (mm).

Table 7. Parameter values used to define the steel bar quadrilinear tensile law.

Table 8. Parameter values of the post-cracking trilinear relationship for the concrete bulk.

Table 9. Estimated fracture energy of concrete compositions reinforced with $60 / .80$ fibres.

Table 10. Relations between the maximum load and displacement for each simulation and its experimental results (same material law).

Table 11. Relations between the maximum load and displacement for each simulation and its experimental results (same fracture energy). 
Table 1. Self-compacting concrete mixes [per $\mathrm{m}^{3}$ ].

\begin{tabular}{ccccccccc}
\hline Constituent & \multicolumn{8}{c}{ Series } \\
\cline { 2 - 9 }$[\mathrm{kg}]$ & $C_{f} 0 f_{c} 50$ & $C_{f} 0 f_{c} 70$ & $C_{f} 60 f_{c} 50$ & $C_{f} 60 f_{c} 70$ & $C_{f} 75 f_{c} 50$ & $C_{f} 75 f_{c} 70$ & $C_{f} 90 f_{c} 50$ & $C_{f} 90 f_{c} 70$ \\
\hline Cement & 420 & 480 & 420 & 480 & 420 & 480 & 420 & 480 \\
Fly ash & 65 & 65 & 65 & 65 & 75 & 75 & 80 & 80 \\
Coarse aggregate & 670 & 628 & 668 & 627 & 661 & 620 & 657 & 619 \\
$\left(D_{\max }=12 \mathrm{~mm}\right)$ & & & & & & & & \\
Coarse Sand & 806 & 757 & 804 & 755 & 795 & 746 & 790 & 741 \\
Fine sand & 269 & 253 & 268 & 252 & 265 & 249 & 265 & 247 \\
Superplasticizer & 6.79 & 7.63 & 7.76 & 8.72 & 7.92 & 8.88 & 8.00 & 8.96 \\
Water & 165 & 185 & 165 & 185 & 168 & 189 & 170 & 190 \\
Fibres & 0 & 0 & 60 & 60 & 75 & 75 & 90 & 90 \\
\hline
\end{tabular}


Table 2. Average values of the tensile properties of the steel bars used in the flexural reinforcement of the slabs.

\begin{tabular}{cccccc}
\hline Diameter $(\mathrm{mm})$ & $\varepsilon_{s y}(\%)$ & $f_{s y}(\mathrm{MPa})$ & $\varepsilon_{s u}(\%)$ & $f_{s u}(\mathrm{MPa})$ & $E_{s}(\mathrm{GPa})$ \\
\hline 12 & 2.53 & 530 & - & 684 & 209.49 \\
\hline
\end{tabular}


Table 3. Content of fibres in the notched plane of SFRSCC beam bending tests, and the determined content of fibres.

\begin{tabular}{ccccc}
\hline Series & $\begin{array}{c}\text { Depth of the notched } \\
\text { cross section }(\mathrm{mm})\end{array}$ & $\mathrm{N}^{\mathrm{o}}$ of fibres $\left(N_{f}\right)$ & $\begin{array}{c}\text { Fibres per unit area } \\
\left(N_{f} / \mathrm{cm}^{2}\right)\end{array}$ & $\begin{array}{c}\text { Determined content of fibres } \\
\left(\mathrm{kg} / \mathrm{m}^{3}\right)\end{array}$ \\
\hline$C_{f} 60 f_{c} 50$ & 125 & 166 & 0.89 & 30 \\
$C_{f} 60 f_{c} 70$ & 125 & 295 & 1.58 & 53 \\
$C_{f} 75 f_{c} 50$ & 107.5 & 155 & 0.96 & 32 \\
$C_{f} 75 f_{c} 70$ & 107.5 & 416 & 2.58 & 86 \\
$C_{f} 90 f_{c} 50$ & 90 & 305 & 2.26 & 76 \\
$C_{f} 90 f_{c} 70$ & 90 & 317 & 2.34 & 79 \\
\hline
\end{tabular}


Table 4. Main results obtained in the punching tests.

\begin{tabular}{cccccc}
\hline Slab & $\begin{array}{c}P_{\max } \\
(\mathrm{kN})\end{array}$ & $\begin{array}{c}\delta_{P_{\max }} \\
(\mathrm{mm})\end{array}$ & $P_{\max }^{S F R C C} / P_{\max }^{R E F}$ & $\delta_{\max }^{S F S C C} / \delta_{\max }^{R E F}$ & Failure mode \\
\hline$C_{f} 0 f_{c} 50$ & 409.11 & 26.58 & - & - & Punching \\
$C_{f} 0 f_{c} 70$ & 399.15 & 25.09 & - & 1.06 & Punching \\
$C_{f} 60 f_{c} 50$ & 386.08 & 28.23 & 0.94 & 1.54 & Punching \\
$C_{f} 60 f_{c} 70$ & 462.03 & 38.63 & 1.16 & 1.04 & Bending \\
$C_{f} 75 f_{c} 50$ & 408.03 & 27.56 & 1.00 & 1.94 & Punching \\
$C_{f} 75 f_{c} 70$ & 496.34 & 48.79 & 1.24 & 1.72 & Bending \\
$C_{f} 90 f_{c} 50$ & 456.53 & 45.81 & 1.12 & 2.02 & Bending \\
$C_{f} 90 f_{c} 70$ & 495.58 & 50.77 & 1.24 & & Bending/Punching \\
\hline
\end{tabular}


Table 5. Residual flexural strengths, $f_{\mathrm{R}, \mathrm{i}}$, obtained in the three-point bending tests.

\begin{tabular}{|c|c|c|c|c|c|c|}
\hline Series & $\begin{array}{c}\text { N. specimens } \\
{[-]}\end{array}$ & $\begin{array}{c}\text { Notch depth } \\
{[\mathrm{mm}]}\end{array}$ & $\begin{array}{c}f_{\mathrm{R}, 1} \\
{[\mathrm{MPa}]}\end{array}$ & $\begin{array}{c}f_{\mathrm{R}, 2} \\
{[\mathrm{MPa}]}\end{array}$ & $\begin{array}{c}f_{\mathrm{R}, 3} \\
{[\mathrm{MPa}]}\end{array}$ & $\begin{array}{c}f_{\mathrm{R}, 4} \\
{[\mathrm{MPa}]}\end{array}$ \\
\hline$C_{f} O f_{c} 50$ & - & - & - & - & - & - \\
\hline$C_{f} O f_{c} 70$ & - & - & - & - & - & - \\
\hline$C_{f} 60 f_{c} 50$ & 9 & 25 & $\begin{array}{c}5.92 \\
(20.9 \%)\end{array}$ & $\begin{array}{c}4.28 \\
(19.5 \%)\end{array}$ & $\begin{array}{c}2.74 \\
(21.8 \%)\end{array}$ & $\begin{array}{c}1.96 \\
(29.9 \%)\end{array}$ \\
\hline$C_{f} 60 f_{c} 70$ & 9 & 25 & $\begin{array}{c}9.54 \\
(13.4 \%)\end{array}$ & $\begin{array}{c}10.08 \\
(10.7 \%)\end{array}$ & $\begin{array}{c}8.37 \\
(14.3 \%)\end{array}$ & $\begin{array}{c}6.90 \\
(17.5 \%)\end{array}$ \\
\hline$C_{f} 75 f_{c} 50$ & 9 & 42.5 & $\begin{array}{c}6.35 \\
(23.9 \%)\end{array}$ & $\begin{array}{c}5.30 \\
(18.1 \%)\end{array}$ & $\begin{array}{c}3.21 \\
(23.0 \%)\end{array}$ & $\begin{array}{c}2.16 \\
(31.6 \%)\end{array}$ \\
\hline$C_{f} 75 f_{c} 70$ & 7 & 42.5 & $\begin{array}{c}12.39 \\
(13.4 \%)\end{array}$ & $\begin{array}{c}13.01 \\
(11.7 \%)\end{array}$ & $\begin{array}{c}11.74 \\
(16.1 \%)\end{array}$ & $\begin{array}{c}10.54 \\
(19.3 \%)\end{array}$ \\
\hline$C_{f} 90 f_{c} 50$ & 9 & 60 & $\begin{array}{c}12.31 \\
(15.4 \%)\end{array}$ & $\begin{array}{c}14.24 \\
(16.3 \%)\end{array}$ & $\begin{array}{c}12.77 \\
(21.1 \%)\end{array}$ & $\begin{array}{c}10.73 \\
(25.3 \%)\end{array}$ \\
\hline$C_{f} 90 f_{c} 70$ & 7 & 60 & $\begin{array}{c}11.55 \\
(22.5 \%) \\
\end{array}$ & $\begin{array}{c}13.33 \\
(21.0 \%) \\
\end{array}$ & $\begin{array}{c}12.08 \\
(24.8 \%) \\
\end{array}$ & $\begin{array}{c}10.57 \\
(31.0 \%) \\
\end{array}$ \\
\hline
\end{tabular}


Table 6. Thickness of the layers in the shell element ( $\mathrm{mm})$.

\begin{tabular}{llcccccc}
\hline \multirow{2}{*}{ Slab } & \multirow{2}{*}{ Zone } & \multicolumn{2}{c}{ Concrete } & \multicolumn{3}{c}{ Steel } & \multicolumn{3}{c}{ Cover Concrete } \\
\cline { 3 - 8 } & & Layer & Thick & Layer & Thick & Layer & Thick \\
\hline \multirow{2}{*}{ Reference } & 2 & {$[1-10]$} & 12.238 & 11 & 1.244 & {$[12-15]$} & 6.595 \\
& 3 & {$[1-10]$} & 12.265 & 11 & 0.693 & {$[12-15]$} & 6.664 \\
& 1 & {$[1-10]$} & 12.293 & 11 & 0.141 & {$[12-15]$} & 6.733 \\
\hline \multirow{2}{*}{ SFRSCC } & 2 & {$[1-10]$} & 12.269 & 11 & 1.244 & {$[12-15]$} & 6.595 \\
& 3 & & & {$[1-15]$} & 10.000 & {$[12-15]$} & 6.672 \\
\end{tabular}


Table 7. Parameter values used to define the steel bar quadrilinear tensile law.

\begin{tabular}{cccccccc}
\hline $\begin{array}{c}\sigma_{n, 1}^{c r} \\
(\mathrm{MPa})\end{array}$ & $\begin{array}{c}\sigma_{n, 2}^{c r} \\
(\mathrm{MPa})\end{array}$ & $\begin{array}{c}\sigma_{n, 3}^{c r} \\
(\mathrm{MPa})\end{array}$ & $\begin{array}{c}\sigma_{n, 4}^{c r} \\
(\mathrm{MPa})\end{array}$ & $\begin{array}{c}\varepsilon_{n, 2}^{c r} \\
(\%)\end{array}$ & $\begin{array}{c}\varepsilon_{n, 3}^{c r} \\
(\%)\end{array}$ & $\begin{array}{c}\varepsilon_{n, 4}^{c r} \\
(\%)\end{array}$ & $\begin{array}{c}G_{f}^{I} \\
(\mathrm{~N} / \mathrm{mm})\end{array}$ \\
\hline 467.01 & 511.99 & 531.39 & 584.00 & 0.72 & 1.84 & 7.74 & 390.30 \\
\hline
\end{tabular}


Table 8. Parameter values of the post-cracking trilinear relationship for the concrete bulk.

\begin{tabular}{ccccccc}
\hline Series & Layer & $\xi_{1}(-)$ & $\xi_{2}(-)$ & $\alpha_{1}(-)$ & $\alpha_{2}(-)$ & $\begin{array}{c}G_{f}^{I} \\
(\mathrm{~N} / \mathrm{mm})\end{array}$ \\
\hline$C f 0 f c 50$ & - & 0.100 & 0.999 & 0.095 & 0.000 & 0.08 \\
$C f 60 f c 50$ & {$[1-10]$} & & & & & {$[1.25-0.16]$} \\
$C f 75 f c 50$ & {$[12-15]$} & 0.033 & 0.250 & 0.250 & 0.250 & 0.08 \\
$C f 90 f c 50$ & - & 0.005 & 0.100 & 0.300 & 0.200 & 3.50 \\
$C f 0 f c 70$ & - & 0.100 & 0.999 & 0.095 & 0.000 & 0.08 \\
$C f 60 f c 70$ & & 0.025 & 0.800 & 0.250 & 0.250 & 1.00 \\
$C f 75 f c 70$ & & 0.002 & 0.150 & 0.350 & 0.200 & 4.00 \\
$C f 90 f c 70$ & & 0.002 & 0.100 & 0.300 & 0.200 & 3.50 \\
\hline
\end{tabular}


Table 9. Estimated fracture energy of concrete compositions reinforced with 60/.80 fibres.

\begin{tabular}{cccc}
\hline$C_{f}$ & $W_{f}$ & \multicolumn{2}{c}{$G_{f}(\mathrm{~N} / \mathrm{mm})$} \\
$\left(\mathrm{kg} / \mathrm{m}^{3}\right)$ & $(\%)$ & $f_{c}=50(\mathrm{MPa})$ & $f_{c}=70(\mathrm{MPa})$ \\
60 & 2.500 & 10.46 & 11.11 \\
75 & 3.125 & 15.66 & 16.62 \\
90 & 3.750 & 21.79 & 23.12 \\
\hline
\end{tabular}


Table 10. Relations between the maximum load and displacement for each simulation and its experimental results (same material law).

\begin{tabular}{|c|c|c|c|c|c|c|c|c|c|}
\hline \multirow{3}{*}{$\begin{array}{c}C_{f} \\
f_{c m} \\
(\mathrm{MPa})\end{array}$} & \multicolumn{3}{|c|}{$60 \mathrm{~kg} / \mathrm{m}^{3}$} & \multicolumn{3}{|c|}{$75 \mathrm{~kg} / \mathrm{m}^{3}$} & \multicolumn{3}{|c|}{$90 \mathrm{~kg} / \mathrm{m}^{3}$} \\
\hline & $P_{\max }$ & $\delta_{\max }$ & $P_{0.3 m m}$ & $P_{\max }$ & $\delta_{\max }$ & $P_{0.3 m m}$ & $P_{\max }$ & $\delta_{\max }$ & $P_{0.3 \mathrm{~mm}}$ \\
\hline & $\overline{P_{\max }^{\operatorname{Exp}}}$ & $\overline{\delta_{\max }^{E x p}}$ & $\overline{P_{0.3 m m}^{E x p}}$ & $\overline{P_{\max }^{\operatorname{Exp}}}$ & $\overline{\delta_{\max }^{E x p}}$ & $\overline{P_{0.3 m m}^{E x p}}$ & $\overline{P_{\max }^{\operatorname{Exp}}}$ & $\overline{\delta_{\max }^{E x p}}$ & $\overline{P_{0.3 m m}^{E x p}}$ \\
\hline 50 & 1.163 & 0.826 & 1.154 & 1.526 & 1.207 & 1.177 & 1.857 & 1.793 & 1.311 \\
\hline 70 & 1.276 & 0.693 & 1.255 & 1.485 & 1.333 & 1.152 & 1.692 & 1.467 & 1.182 \\
\hline
\end{tabular}


Table 11. Relations between the maximum load and displacement for each simulation and its experimental results (same fracture energy).

\begin{tabular}{cccccccccc}
\hline$f_{c m}$ & $P_{\max }$ & $\frac{\delta_{\max }}{\delta_{\text {max }}^{E x p}}$ & $\frac{P_{0.3 m m}}{P_{0.3 m m}^{E x p}}$ & $\frac{P_{\max }}{P_{\max }^{E x p}}$ & $\frac{\delta_{\max }}{\delta_{\max }^{E x p}}$ & $\frac{P_{0.3 m m}}{P_{0.3 m m}^{E x p}}$ & $\frac{P_{\max }}{P_{\max }^{E x p}}$ & $\frac{\delta_{\max }}{\delta_{\max }^{E x p}}$ & $\frac{P_{0.3 m m}}{P_{0.3 m m}^{E x p}}$ \\
\hline $\mathrm{MPa})$ & 1.120 & 1.207 & 0.974 & 1.088 & 1.000 & 1.164 & 1.089 & 0.828 & 1.315 \\
70 & 1.060 & 1.026 & 1.024 & 1.205 & 1.053 & 1.115 & 1.201 & 0.947 & 1.181 \\
\hline
\end{tabular}




\section{LIST OF FIGURE CAPTIONS}

Figure 1. Geometry of the slab prototype (dimensions in $\mathrm{mm}$ ).

Figure 2. Flexural reinforcement in: a) reference slabs, b) SFRC slabs; Cross section of c) AA, and d) BB (dimensions in $\mathrm{mm})$.

Figure 3. Test setup: a) Top view, b) Bottom view.

Figure 4. Load versus centre deflection in the tested series: a) $50 \mathrm{MPa}$, b) $70 \mathrm{MPa}$.

Figure 5. Relationships between $P_{\max }$ and the residual flexural tensile strengths: a) $f_{R, 1}$; b) $f_{R, 2} ;$ c) $f_{R, 3} ;$ d) $f_{R, 4}$

Figure 6. Trilinear stress-strain diagram to simulate the fracture mode I crack propagation.

Figure 7. Generic diagram to simulate the relationship between the out-of-plane (OP) shear stress and shear strain components.

Figure 8. a) Mesh, supports and symmetry conditions adopted; b) Layer discretization of the slab's cross section.

Figure 9. Experimental and numerical results (50 MPa).

Figure 10. Experimental and numerical results (70 MPa).

Figure 11. Curves load-displacement for different values of fracture energy. a) $\left.f_{c}=50 \mathrm{MPa}, \mathrm{b}\right) f_{c}=70 \mathrm{MPa}$.

Figure 12. Different material laws considered. a) $f_{c}=50 \mathrm{MPa}$, b) $f_{c}=70 \mathrm{MPa}$.

Figure 13. Curves load-displacement for different shapes of the material law. a) $f_{c}=50 \mathrm{MPa}$, b) $f_{c}=70 \mathrm{MPa}$. 


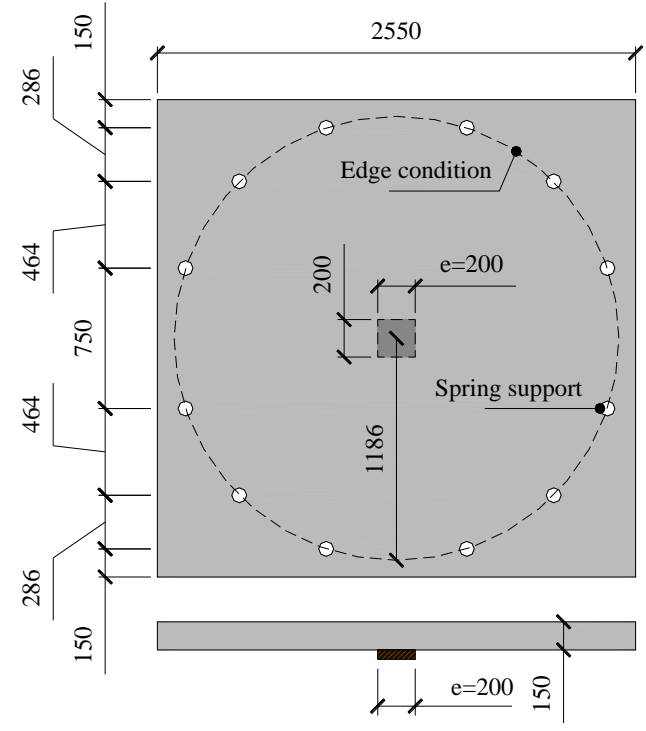

Figure 1. Geometry of the slab prototype (dimensions in $\mathrm{mm}$ ) [18]. 


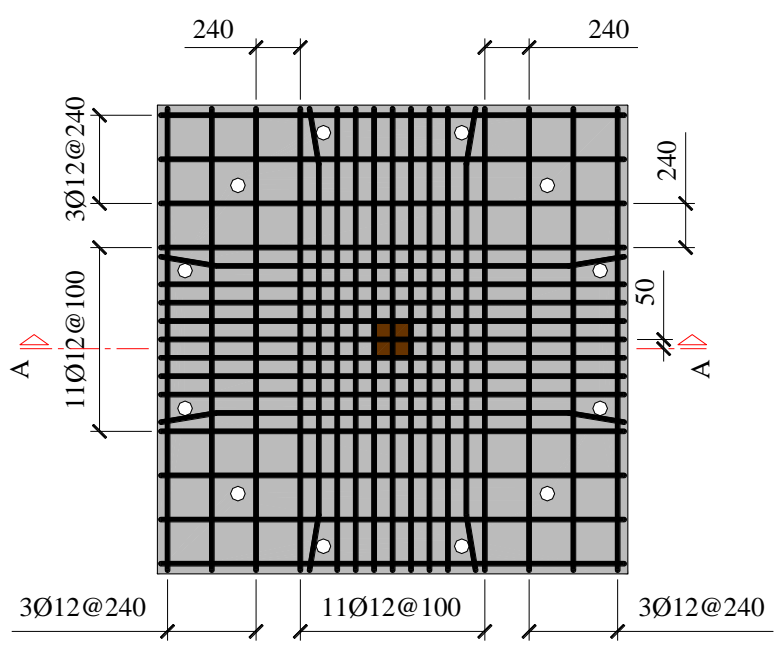

a)

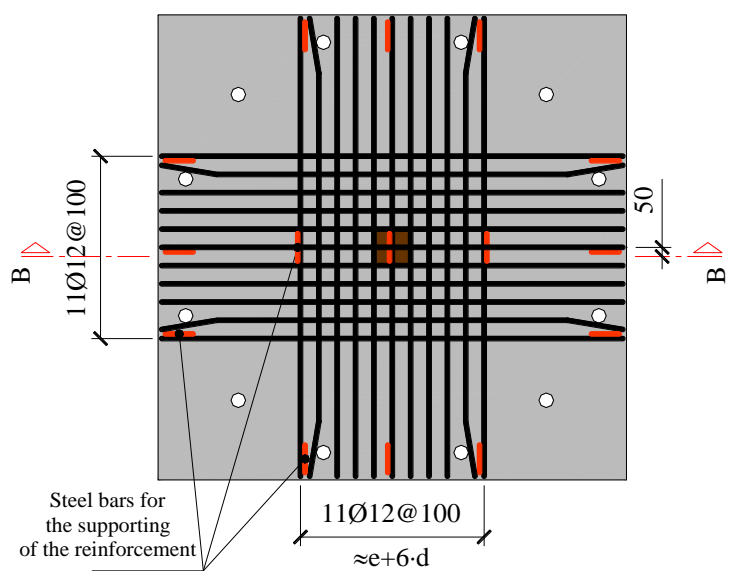

b)

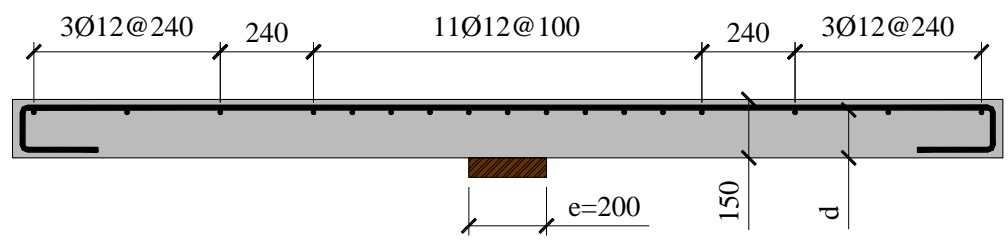

c)

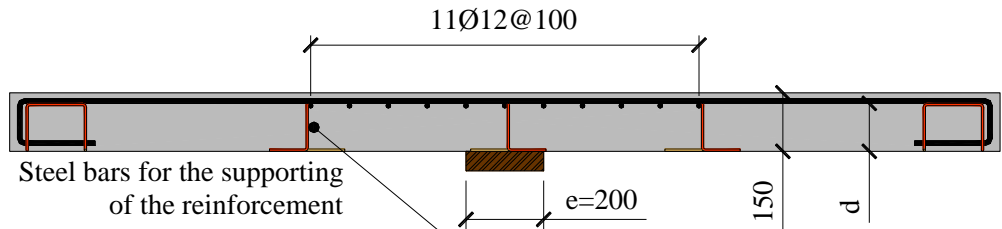

d)

Figure 2. Flexural reinforcement in: a) reference slabs, b) SFRSCC slabs; Cross section of c) AA, and d) BB (dimensions in $\mathrm{mm}$ ) [18]. 


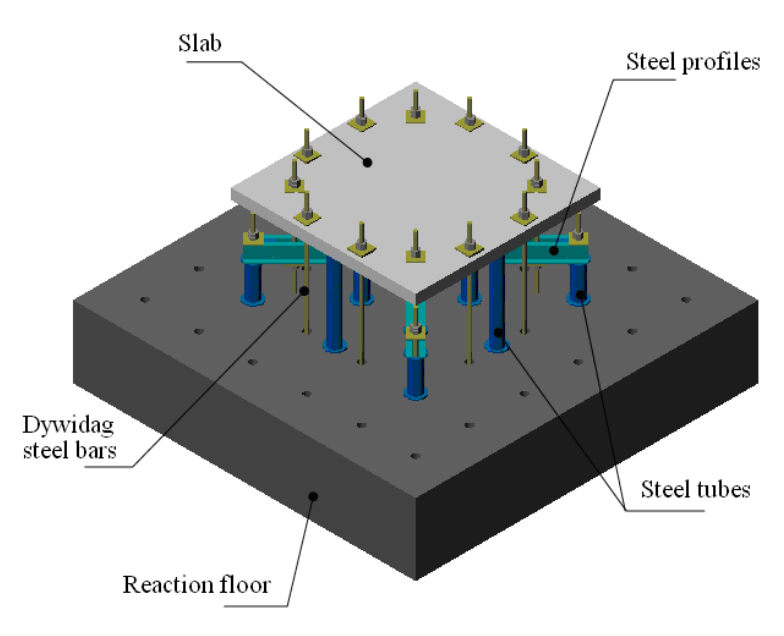

a)

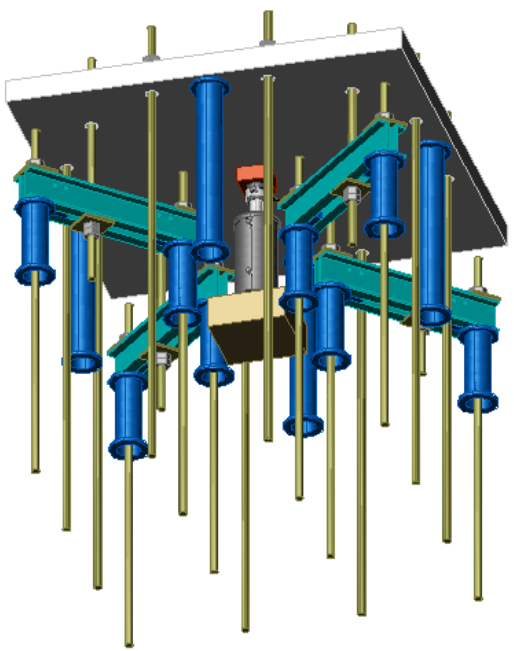

b)

Figure 3. Test setup: a) Top view, b) Bottom view [18]. 


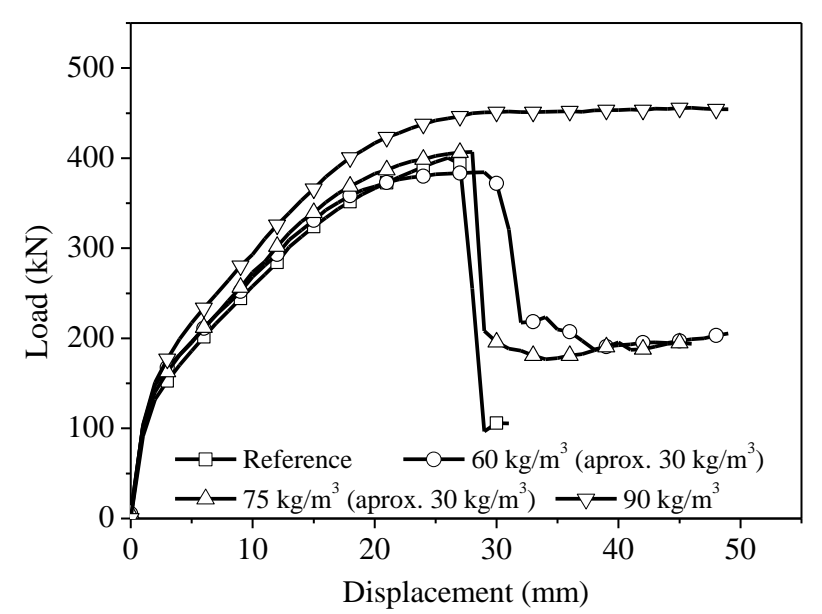

a)

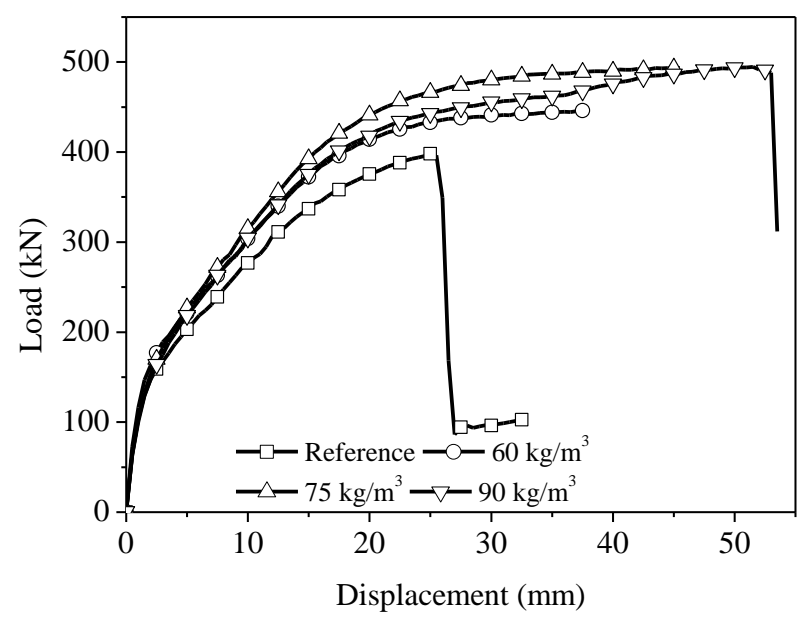

b)

Figure 4. Load versus centre deflection in the tested series: a) $50 \mathrm{MPa}$, b) $70 \mathrm{MPa}$. 


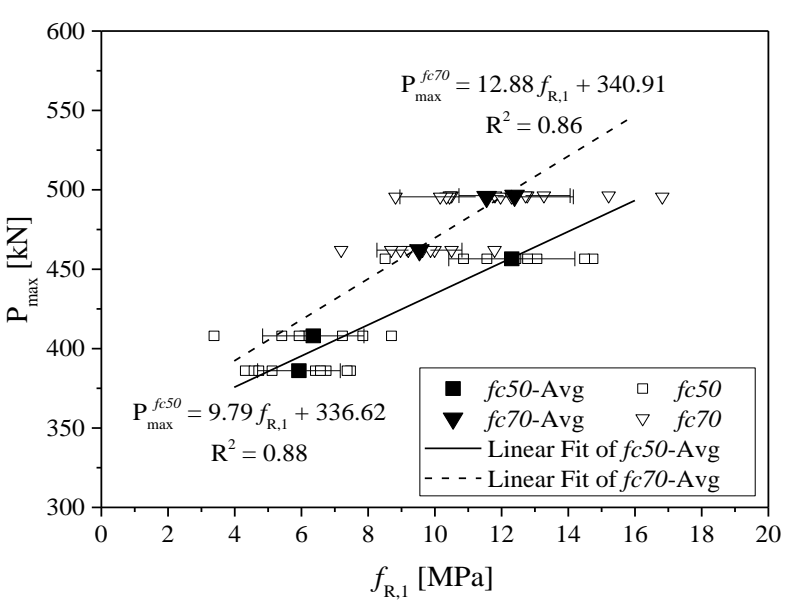

a)

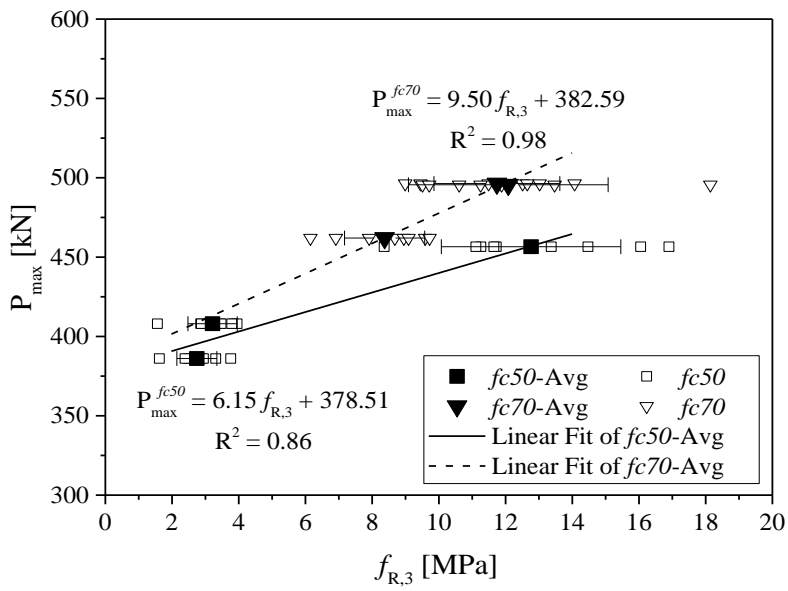

c)

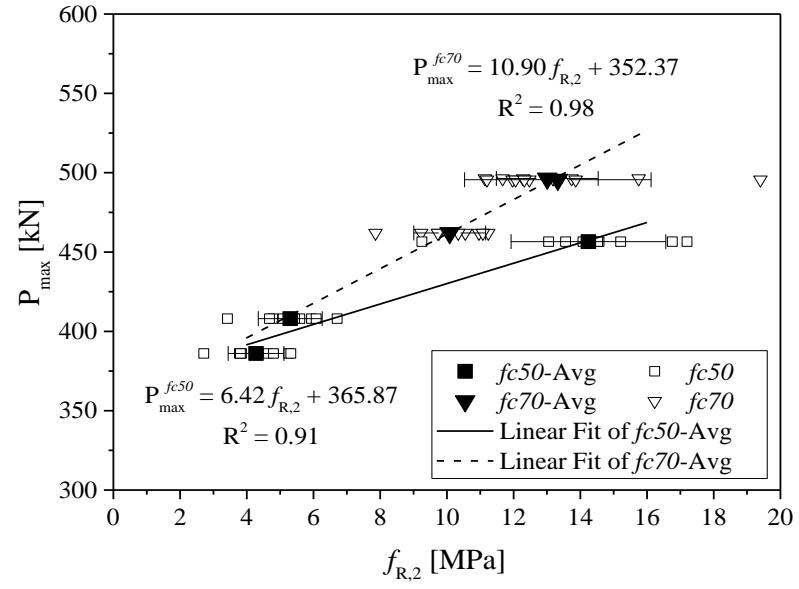

b)

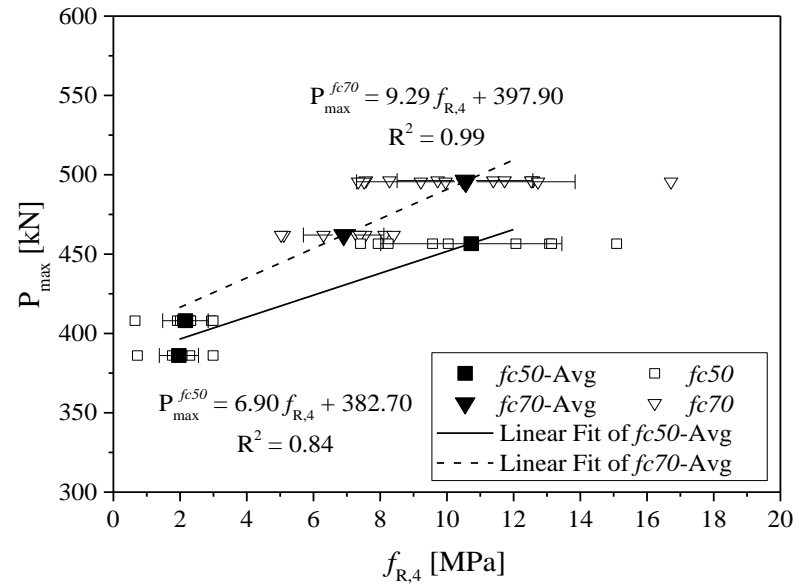

d)

Figure 5. Relationships between $P_{\max }$ and the residual flexural tensile strengths: a) $f_{R, 1}$; b) $f_{R, 2}$; c) $f_{R, 3}$; d) $f_{R, 4}$ 


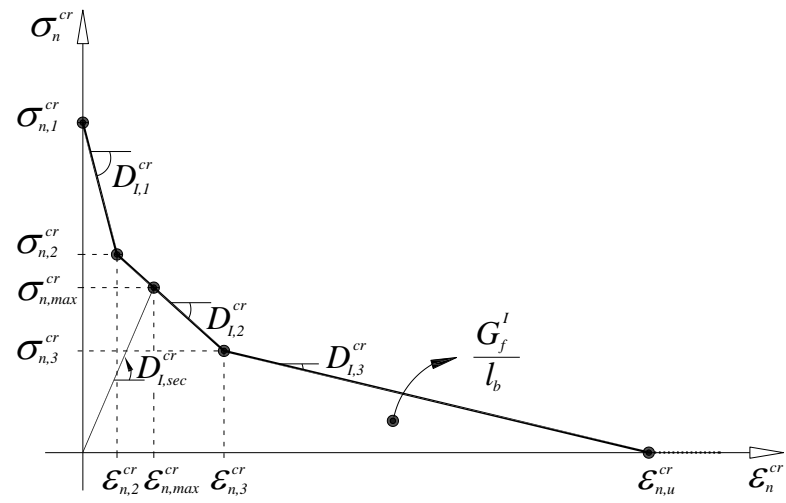

Figure 6. Trilinear stress-strain diagram to simulate the fracture mode I crack propagation ( $\sigma_{n, 1}^{c r}=f_{c t}, \sigma_{n, 2}^{c r}=\alpha_{1} \sigma_{n, 1}^{c r}$, $\left.\sigma_{n, 3}^{c r}=\alpha_{2} \sigma_{n, l}^{c r}, \varepsilon_{n, 2}^{c r}=\xi_{1} \varepsilon_{n, u}^{c r}, \varepsilon_{n, 3}^{c r}=\xi_{2} \varepsilon_{n, u}^{c r}\right)$. 


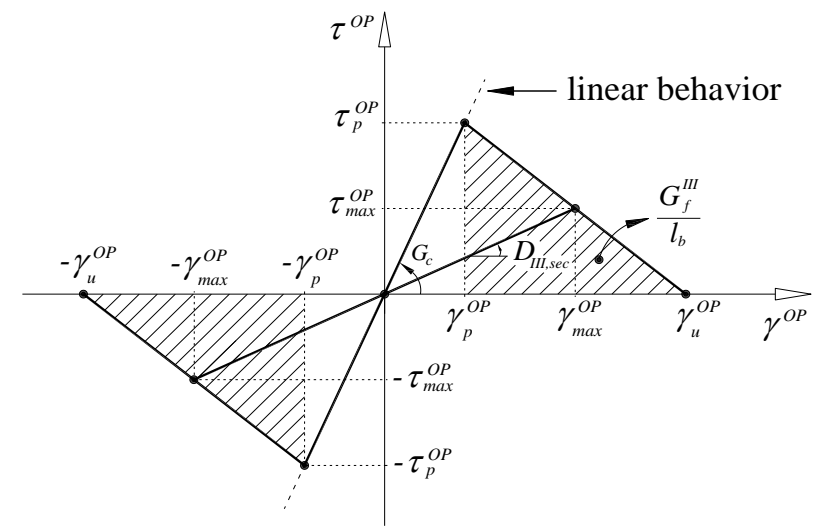

Figure 7. Generic diagram to simulate the relationship between the out-of-plane (OP) shear stress and shear strain components. 


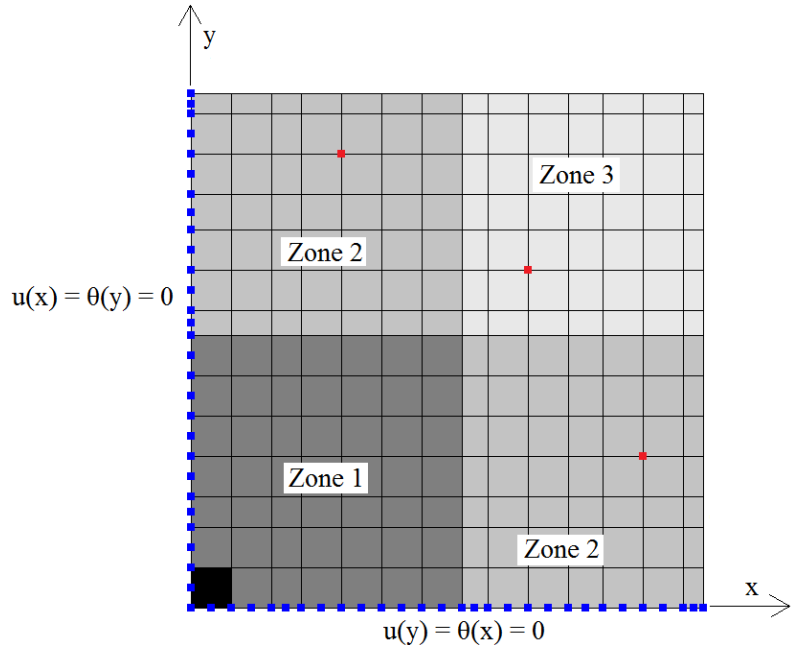

a)

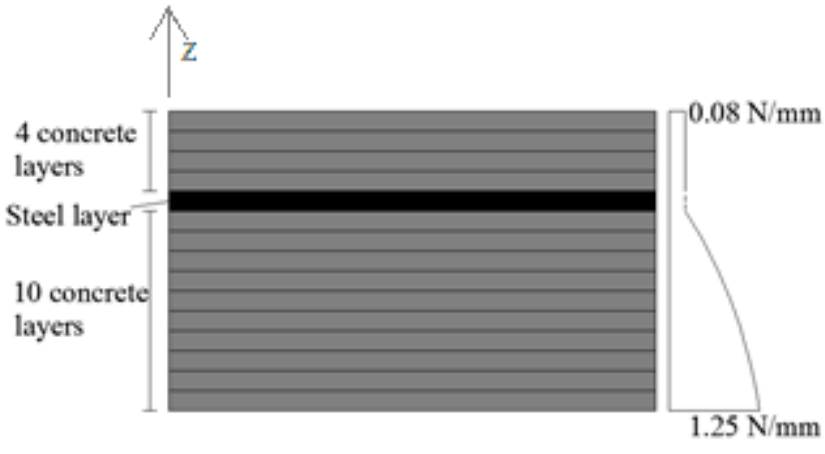

b)

Figure 8. a) Mesh, supports and symmetry conditions adopted; b) Layer discretization of the slab's cross section. 


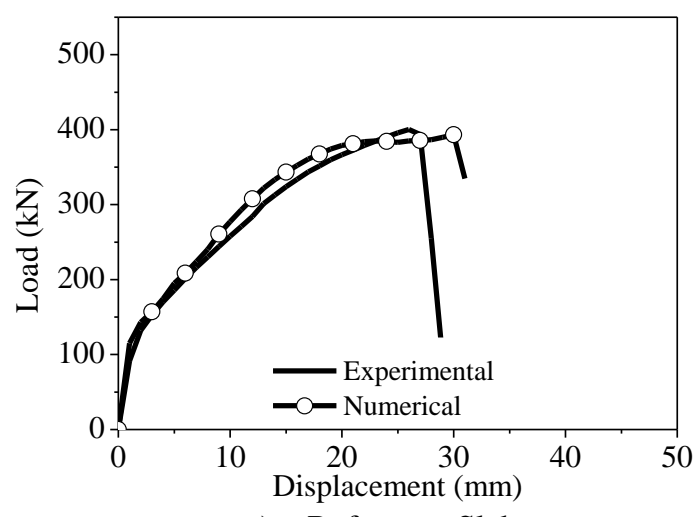

a) Reference Slab

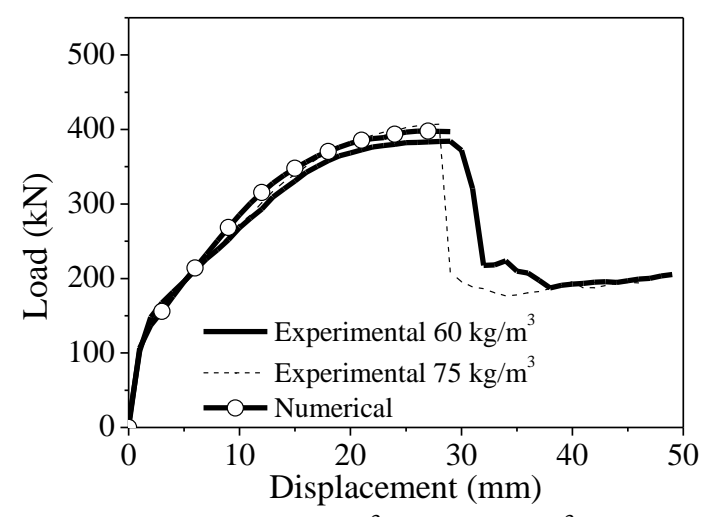

b) $60 \mathrm{~kg} / \mathrm{m}^{3}$ and $75 \mathrm{~kg} / \mathrm{m}^{3}$

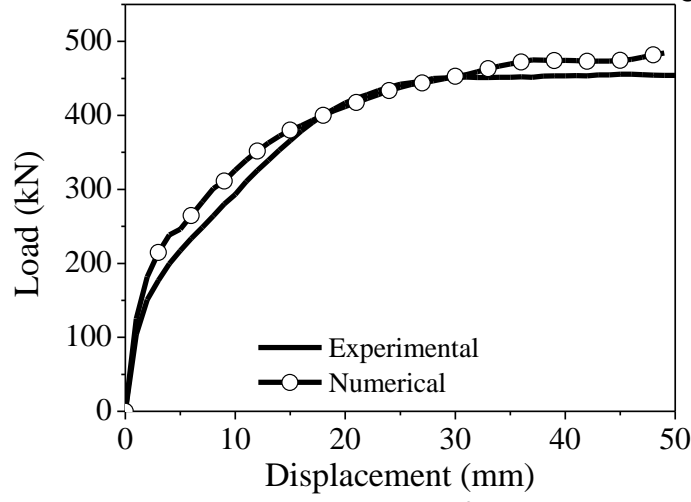

c) $90 \mathrm{~kg} / \mathrm{m}^{3}$

Figure 9. Experimental and numerical results (50 MPa). 


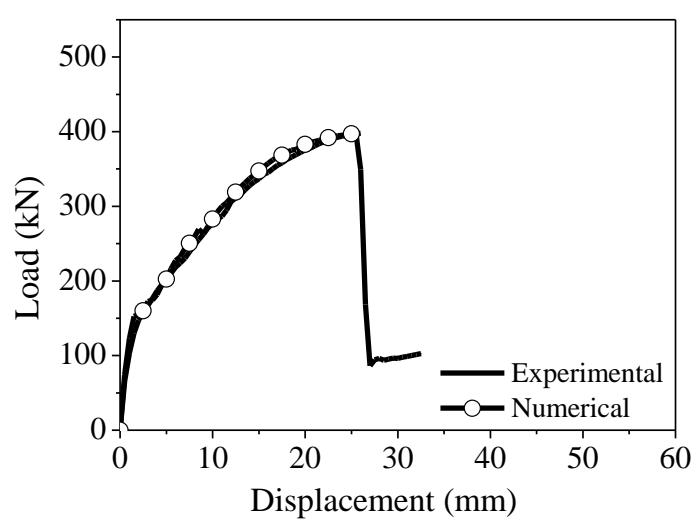

a) Reference Slab

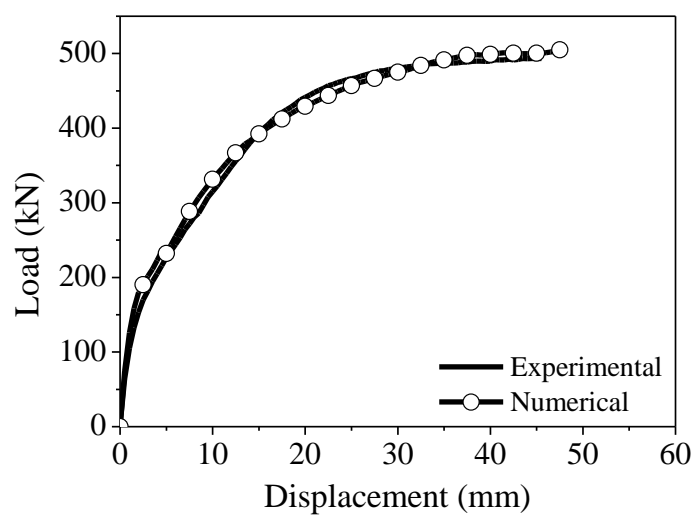

c) $75 \mathrm{~kg} / \mathrm{m}^{3}$

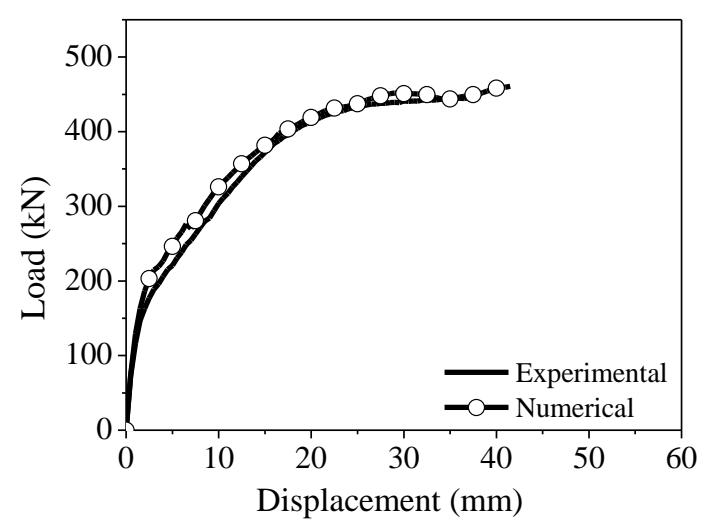

b) $60 \mathrm{~kg} / \mathrm{m}^{3}$

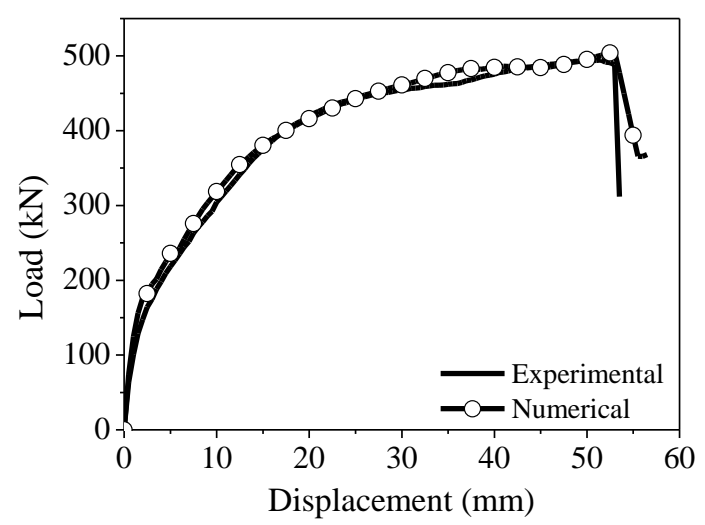

d) $90 \mathrm{~kg} / \mathrm{m}^{3}$

Figure 10. Experimental and numerical results (70 MPa). 


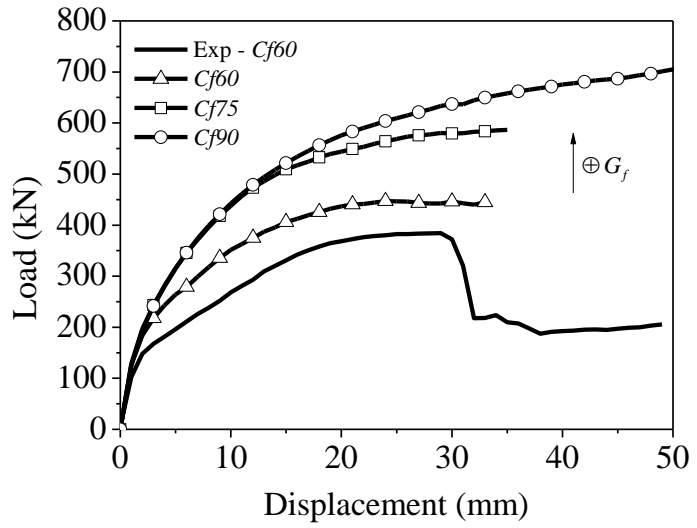

a) $f_{c}=50 \mathrm{MPa}$

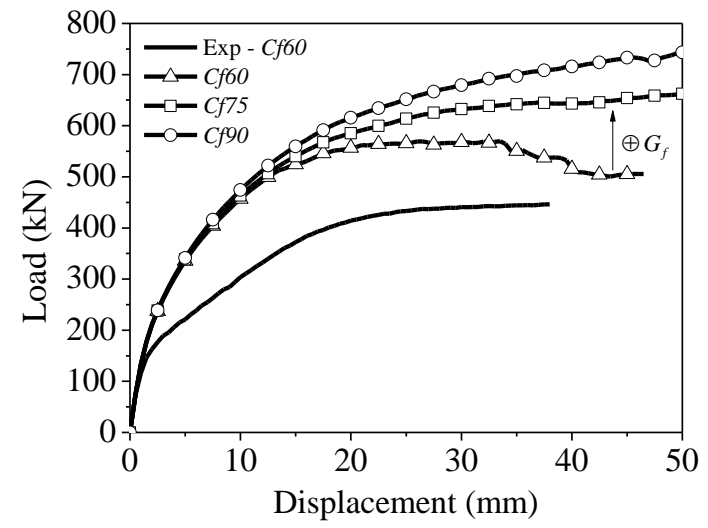

b) $f_{c}=70 \mathrm{MPa}$

Figure 11. Load-displacement curves for distinct fracture energy values. 


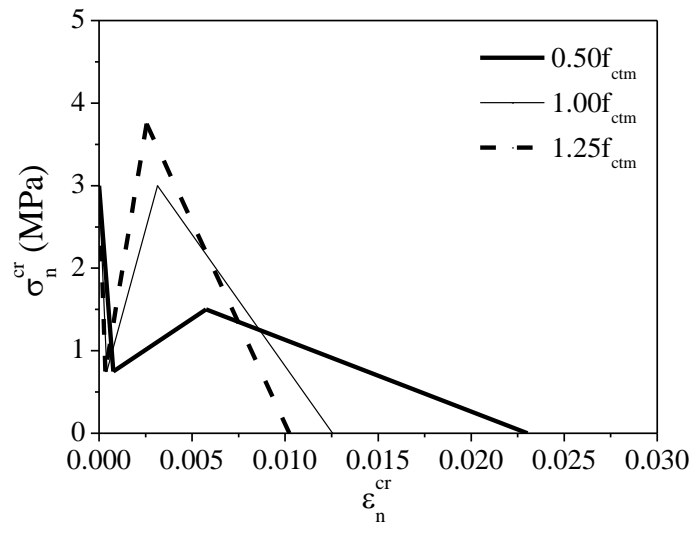

a) $f_{c}=50 \mathrm{MPa}$

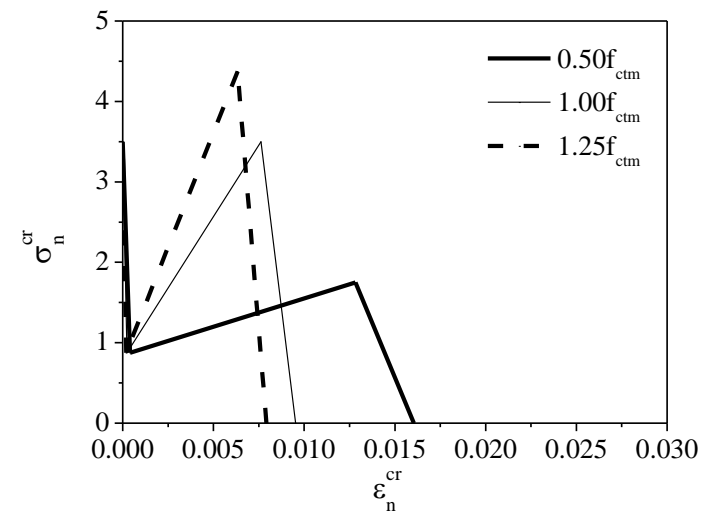

b) $f_{c}=70 \mathrm{MPa}$

Figure 12. Different material laws considered. 


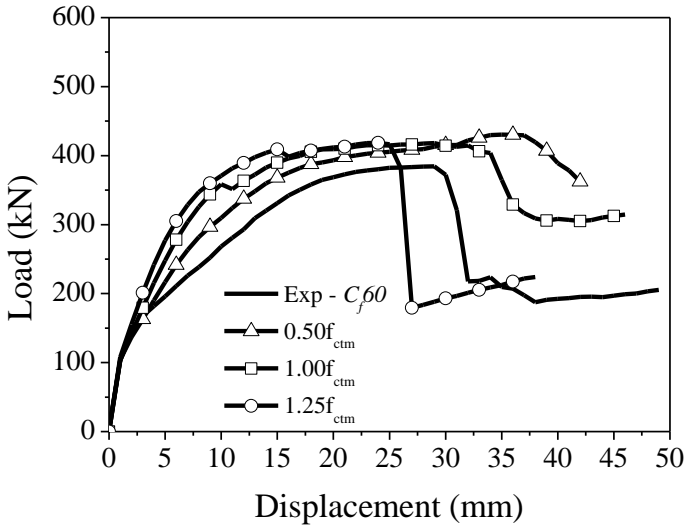

a) $f_{c}=50 \mathrm{MPa}$

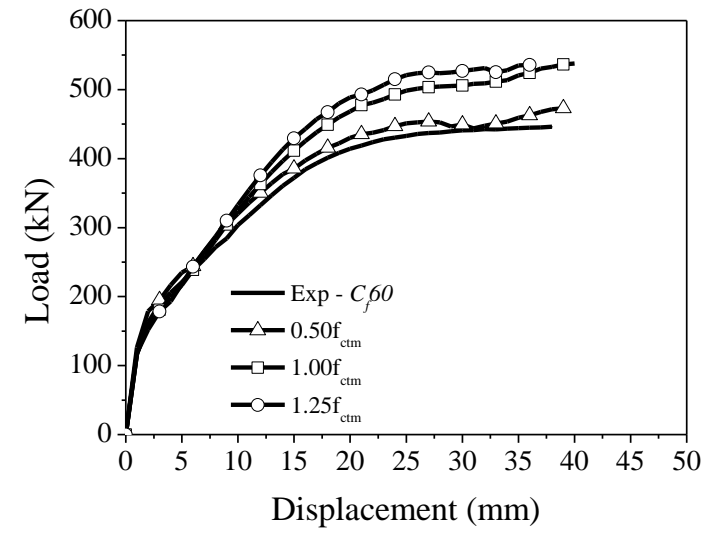

b) $f_{c}=70 \mathrm{MPa}$

Figure 13. Curves load-displacement for different shapes of the material law. 